\title{
Disease drivers of aging
}

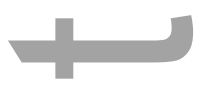

Richard J. Hodes, ${ }^{1}$ Felipe Sierra, ${ }^{1}$ Steven N. Austad, ${ }^{2}$ Elissa Epel, ${ }^{3}$ Gretchen N. Neigh, ${ }^{4}$ Kristine Erlandson, ${ }^{5}$ Marissa J. Schafer, ${ }^{6}$ Nathan K. LeBrasseur, ${ }^{6}$ Christopher Wiley, ${ }^{7}$ Mary E. Sehl, ${ }^{8}$ Marta Epeldegui, ${ }^{8}$ Shehnaz Hussain, ${ }^{8}$ Beth Jamieson, ${ }^{8}$ Steve Horvath, ${ }^{8}$ Oto Martinez-Maza, ${ }^{8}$ Rosario Scalia, ${ }^{9}$ Satoru Eguchi, ${ }^{9}$ Balakuntalam S. Kasinath, ${ }^{10}$ Jeffrey B. Halter, ${ }^{11}$ Harvey Jay Cohen, ${ }^{12}$ Judith Campisi, ${ }^{7}$ Wendy Demark-Wahnefried, ${ }^{13}$ Tim A. Ahles, ${ }^{14}$ Nir Barzilai, ${ }^{15}$ and Arti Hurria ${ }^{16}$

\section{$(2)$}

${ }^{1}$ National Institute on Aging, Baltimore, Maryland. ${ }^{2}$ Department of Biology, University of Alabama at Birmingham, Birmingham, Alabama. ${ }^{3}$ Department of Psychiatry, University of California, San Francisco, San Francisco, California. ${ }^{4}$ Virginia Commonwealth University, Richmond, Virginia. ${ }^{5}$ University of Colorado, Boulder, Colorado. ${ }^{6}$ Robert and Arlene Kogod Center on Aging and Department of Physical Medicine and Rehabilitation, Mayo Clinic College of Medicine, Rochester, Minnesota. ${ }^{7}$ Buck Institute for Research on Aging, Novato, California. ${ }^{8}$ David Geffen School of Medicine, University of California, Los Angeles, Los Angeles, California. ${ }^{9}$ Department of Physiology and Cardiovascular Research Center, Lewis Katz School of Medicine, Temple University,

Philadelphia, Pennsylvania. ${ }^{10}$ Barshop institute for Longevity and Aging Studies, University of Texas Health Science Center, South Texas Veterans Health Care System, San Antonio, Texas. ${ }^{11}$ Division of Geriatric and Palliative Medicine, University of Michigan, Ann Arbor, Michigan. ${ }^{12}$ Duke University School of Medicine, Durham, North Carolina. ${ }^{13}$ University of Alabama at Birmingham Comprehensive Cancer Center, Birmingham, Alabama.

${ }^{14}$ Memorial Sloan Kettering Cancer Center, New York, New York. ${ }^{15}$ Institute for Aging Research; Albert Einstein College of Medicine, New York, New York. ${ }^{16}$ City of Hope National Medical Center, Duarte, California

Address for correspondence: annals@ @yas.org

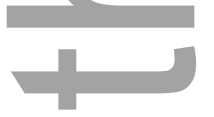

\section{Abstract}

This is the author manuscript accepted for publication and has undergone full peer review but has not been through the copyediting, typesetting, pagination and proofreading process, which may lead to differences between this version and the Version of Record. Please cite this article as doi:

10.1111/nyas.13299.

This article is protected by copyright. All rights reserved. 
It has long been known that aging, at both the cellular and organismal levels, contributes to the development and progression of the pathology of many chronic diseases. However, much less research has examined the inverse relationship - the contribution of chronic diseases and their treatments to the progression of aging-related phenotypes. Here, we discuss the impact of three chronic diseases (cancer, HIV/AIDS, and diabetes) and their treatments on aging, putative mechanisms by which these effects are mediated, and the open questions and future research directions required to understand the relationships between these diseases and aging.

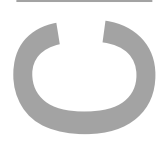

Keywords: disease; aging; pathology; chronic; prevention; age-related; HIV; diabetes; cancer

\section{Introduction}

The geroscience hypothesis, that aging is the major modifiable risk factor for most chronic diseases, is currently well accepted and it is being tested in multiple models and systems, ranging from basic biology in a variety of organisms to preclinical and clinical studies. Aging has been recognized for years as a major risk factor for most chronic diseases that affect the aged population. However, it has traditionally been overlooked as a non-modifiable risk factor, and thus neglected in most of our approaches to medicine. This has changed recently because of the recognition, among basic biology of aging researchers, of a limited number of pillars that seem to be the main drivers of the aging process. Identification of these pillars was made possible by a multipronged approach based on the now classical tenets of aging biology: caloric restriction, cell senescence, and free radicals. While the initial theories and concepts driving each of these fields have been subjected to modifications and redefinitions, research based on these tenets has allowed researchers to identify the major drivers of the process. This in turn has led to the beginnings of efforts aimed at translating the findings through the use of pharmacological approaches aimed at one or more of the pillars of aging, with the hope that, by addressing these fundamental drivers, a positive impact might be achieved in combating not one, but multiple chronic diseases in parallel.

This article is protected by copyright. All rights reserved. 
On the other hand, it is well established that aging and disease susceptibility are highly variable among individuals within the human population, most likely due to variations in the wellknown interactions between genes and environment. Against this background, a major environmental variable known epidemiologically to affect the "rate of aging" (colloquially understood, as there is no agreed-upon definition or measure for the rate of aging) is exposure to early serious disease. It has been well established, at the epidemiological level, that early exposure to severe diseases and/or their treatments leads to an acceleration of aging, as defined by an increased and premature risk of developing diseases and conditions that are associated with increased age. In order to narrow the discussion, in the Second Geroscience Summit, held on April 13-14, 2016 in New York, New York, we focused on three examples: cancer, HIV/AIDS, and diabetes. This was driven simply by the need to limit the scope of the discussions, but it is expected that the issues raised will apply, with modifications, to all or most diseases that, while curable, nevertheless leave sequelae that are likely to affect later increased susceptibility to age-related diseases and conditions.

That serious disease and/or their treatments lead to an acceleration of disease susceptibility later in life is well established at the epidemiological level. The goal of the summit was to dig further and try to assess possible molecular and cellular mechanisms that might be responsible for the epidemiological observations. A specific emphasis was placed on links between diseases and/or treatment and the major pillars of aging, with the assumption that if these early life events affect some of the same pillars that have been associated with aging, then this should be a good place to start addressing the relationship between the two.

\section{Geroscience as a multidisciplinary approach to understanding aging}

Richard J. Hodes

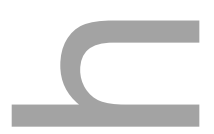

The extramural program of the National Institute on Aging (NIA) at the National Institutes of Health $(\mathrm{NIH})$ is organized around four divisions, and each is poised to make unique and substantive contributions to the field of geroscience. The Division of Aging Biology is the lead for geroscience at the NIA, and its focus is on the basic biochemical, genetic, and physiological mechanisms underlying the process of aging and age-related changes in humans and in animal models of human aging. Geroscience is a natural extension of this work. The Division of Neuroscience focuses on the 
dementias of old age, as well as understanding the processes associated with the normally aging brain. The basic science research funded by this division intersects with geroscience in the areas of biologic mechanisms of disease (e.g., dementias) and age-related changes in the brain that lead to increased disease risk. The Division of Behavioral and Social Research explores aging at the individual and the societal level - and research in areas like the biological mediators of social stressors provides a connection to geroscience. Lastly, the NIA's Division of Geriatrics and Clinical Gerontology supports research on health and disease in the aged and research on aging over the human life span; its focus on aging-related diseases offers a close link to geroscience.

Similar connections can be made throughout the NIH. The NIH comprises 27 different institutes and centers (ICs), and nearly all of them investigate at least some diseases and conditions for which aging is a risk factor. Aging-related changes affect bodily functions at every level, from cellular metabolism and inflammatory responses to proteostasis and epigenetic modifications. These changes that occur with age have been termed the "pillars of geroscience" (Fig. 1). It is the intersection of these processes with the mechanisms underlying many critical aging-related diseases that drives a common interest for NIA and the NIH ICs that support research on these diseases.

The need to raise awareness of the role of aging biology in disease development prompted the NIA - along with 20 other ICs at the NIH - to form a geroscience interest group (GSIG). The GSIG helped to organize an initial Geroscience Summit in 2013, which resulted in several activities, including papers, a book, and some multi-institute funding opportunity announcements. Continued $\mathrm{NIH}$ and extramural community interest in the field led to the organization of a second summit, reported here, in April 2016.

Over the past several years, a number of science advances illustrate these connections and, importantly, the unique role that aging can play in disease development, as well as in responses to disease interventions. One of the most significant NIA-supported findings of this type was the result from the Diabetes Prevention Program studies - led by the National Institute of Diabetes and Digestive and Kidney Diseases - that showed an especially profound effect of a lifestyle intervention in preventing diabetes in individuals over 60 , relative to the effect of the same intervention in younger participants. ${ }^{3}$ Basic science studies have also demonstrated the potentially life-saving importance of preclinical testing of therapies in older animals. A 2013 study by Bouchlaka et al. ${ }^{4}$ found that one systemic cancer immunotherapy strategy was $100 \%$ lethal to older mice after $48 \mathrm{~h}$, yet all of the younger animals tested survived and were in fact helped by the therapy.

This article is protected by copyright. All rights reserved. 
The geroscience pillars will continue to inform this work as more of it moves from the bench through translational research applications to clinical trials. As just one example, it has been reported that removal of senescent cells from an aging mouse through an innovative genetic strategy results in enhanced structure and function of muscle and other tissue. ${ }^{5}$ These and other recent findings in model systems provide a basis for translation into clinical studies - and meetings like the summit are designed to catalyze these discoveries.

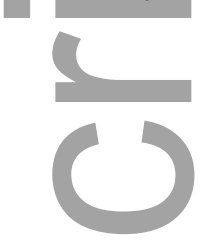

\section{Disease drivers of aging as a topic of geroscience}

Felipe Sierra

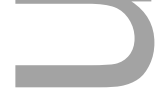

Aging is recognized as the major risk factor for most chronic diseases and disabilities. However, there is still a widespread perception that aging is immutable, and thus both research and clinical trials often focus on curing or preventing specific diseases rather than addressing the core: aging itself. Against this background, researchers have made impressive progress in the last few decades in understanding the genetics, biology, and physiology of aging, using a veritable zoo of laboratory animals to model human aging. ${ }^{6}$ This has made possible the emergence of the field of geroscience, the intersection between basic aging biology and disease. ${ }^{7}$ The aims of geroscience are to understand the molecular and cellular basis of how aging enables disease and to exploit that knowledge. Indeed, the geroscience hypothesis states that, by reducing the rate of aging, it should be possible to delay or slow down the appearance and progression of not one, but most age-related chronic ailments, all at once. ${ }^{8}$ This includes life-threatening diseases, such as cancer, vascular disease, diabetes, and many others, as well as chronic diseases (arthritis, osteoporosis, mild cognitive impairment) and conditions (frailty, loss of resilience, fatiguability) that, while not life threatening themselves, nevertheless severely diminish quality of life.

The trans-NIH GeroScience Interest Group (GSIG) was formed with the goal of promoting awareness and discussion on these issues. A major activity of the GSIG has been the summits. The first Geroscience Summit, in October 2013, focused on exploring the molecular and cellular mechanisms underlying aging as the major risk factor for all chronic diseases. Seven major pillars of 
aging were identified at that time, ${ }^{9}$ and the door was left open for additional pillars not yet identified. One such underexplored pillar could be the appearance of early major diseases and their treatment, which has been shown in epidemiological studies to lead to premature or accelerated appearance of age-specific traits, including chronic morbidity. As a result, a second Geroscience Summit was coorganized by the GSIG in conjunction with the American Federation for Aging Research, the Genetics Society of America, and the New York Academy of Sciences. The meeting was held in April 2016, and it was decided to address the question: What are the molecular and cellular mechanisms that might explain why some diseases accelerate the aging process, leading to premature appearance of age-related diseases and conditions? The fact that there is such an acceleration has been demonstrated extensively in the literature, and therefore further discussion of epidemiological data confirming these results was discouraged. Rather, as in the first summit, the emphasis was on molecular and cellular events occurring as a function of the disease or its treatment that might impinge on the rate of functional deterioration that occurs during normal aging. In an effort to narrow the discussions, three diseases were chosen: HIV/AIDS, diabetes, and cancer. Both the effects of the diseases themselves and the effects of their treatments were discussed by panelists in three separate sessions, as well as a roundtable discussion at the end, focused on identifying open research questions that need to be addressed to advance our understanding of how these diseases might affect the aging process.

While the summit focused separately on the three chosen diseases, it is acknowledged that people of advanced age are rarely affected by a single chronic disease; rather, they are often afflicted by multiple comorbidities and conditions that limit their health. However, during the discussions, the focus was primarily on early appearance of the diseases in relatively young people. In those cases, cancer, HIV/AIDS, and diabetes are often found to occur alone, and the initial disease is often addressed vigorously. This has led to important increases in survival and extended life span in affected individuals. However, comorbidities are observed later, as the patients age, and the summit addressed the downstream consequences, in terms of decreased health span, the portion of life spent in good health

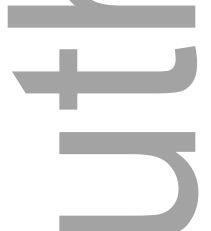

\section{The geroscience hypothesis: what do we know?}

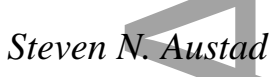

This article is protected by copyright. All rights reserved. 
The progressive deterioration of physiological function over time, aging occurs even in the absence of disease, as shown by the steady decline in performance even of the world's best master athletes as they grow older. However, aging is intimately associated with a wide range of diseases-virtually all the fatal diseases of modern life- because it increases vulnerability to, and compromises the ability to recover from, diseases. Whether diseases themselves can accelerate aging is a hypothesis many researchers are currently considering.

It is important to remember that nonfatal maladies of aging, such as increased joint pain, loss of vision and hearing, and muscle weakness, should not be neglected, as they have become particularly important in recent times. As successful as the biomedical community has become at delaying death, shown by the steady rise of life expectancy for well over a century, it has not been successful at delaying aging itself. Consequently, the number of people needing joint replacement due to chronic pain, cataract surgery due to low vision, or assistance in the simple activities of daily living has steadily risen as well. These chronic fatal and nonfatal maladies of later life have now become the number one threat to human health globally.

In the past 2 decades, the aging research community has been successful at discovering methods to extend the life of model laboratory animals. These methods include genetic, dietary, and pharmaceutical interventions. This research has revealed key players, such as insulin/IGF and mTOR signaling, in complex, interconnected molecular networks that appear to underlie organismal longevity. However, despite these successes, at least three critical questions remain unanswered.

First, do life-extending interventions extend health or do they simply delay death? In terms of their ultimate translation into human therapies, this is perhaps the most important unanswered question. Recently, assessment of age-related health trajectories has become a major focus of laboratory longevity studies. Certainly, extending the unhealthy period of life near its end is not a goal worth pursuing.

Second, will life-extending interventions be effective outside of the laboratory environment? Researchers work very hard to protect their experimental animals from infectious diseases, poor diets, and unpredictable environmental events. Will life — and more importantly health — also be extended in pathogen-rich, unpredictable environments, where substandard diets may be the norm? Some

This article is protected by copyright. All rights reserved. 
interventions, such as dietary restriction, appear to compromise resistance to at least some infectious diseases, ${ }^{10,11}$ so that is a substantial consideration in the real world.

Third, of course, is whether the effects of interventions that were observed in short-lived laboratory species will translate into similar effects in longer-lived species, such as humans. It is well known that only a fraction of interventions that successfully treat cancer in mice have turned out to be therapeutically viable in humans. ${ }^{12}$ So far, not even a fraction of Alzheimer's disease therapies have translated from success in mice to success in humans. ${ }^{13}$

There is no way to determine whether this will be true for known interventions in mouse aging without performing the human trials. Such trials, involving older people as participants, would not need to be excessively lengthy to detect whether health is extended. Multiple drug candidates have already been identified. It is time for the first clinical trial of putative senescence-retarding therapies.
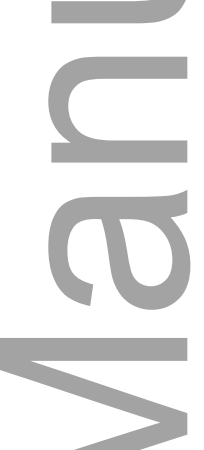

\section{The complex bidirectional relationships between chronic disease and telomere attrition}

Elissa Epel

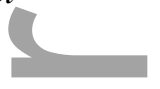

Telomeres are a window into one type of aging - replicative senescence, the inability of mitotic cells to continue to divide and, thus, for tissue to replenish. The most common measure of telomere length in human studies is the average telomere length in blood, across all immune cells. Telomere shortness is an early risk factor for immune senescence. When telomeres reach a critical shortness, the cell enters either senescence or apoptosis. The intracellular enzyme telomerase can promote telomere lengthening, preventing the age-related shortening that comes with cell division.

Telomeres predict disease in humans

Damage to telomeres or an inability to rebuild telomere length after cell division is thought to be a

This article is protected by copyright. All rights reserved. 
very common pathway to cell senescence in in humans, partly because we are so long lived. In lower species, telomeres may be a much less important pathway to senescence. For example, rodents both start out with very long telomeres and live shorter lives. In this case, telomere attrition is only important in extreme examples (knockouts and in subsequent generations when telomeres become very short).

Telomeres in humans are helpful as a marker - they are easy to measure in population-based studies and are predictive of early onset of diseases of aging, as shown by many meta-analyses. Telomere length is also an easy-to-get measure that signals that other likely aspects of cell aging may be present. Short telomeres are bidrectionally related to other aspects of aging biology. For example, dysfunctional telomeres impair mitochondria and lead to systemic inflammation. Telomeres also play a direct mechanistic role in aging, as shown by Mendelian randomization studies (e.g., Ref. 14).

\section{Disease processes may shorten telomeres}

There is now a robust literature showing that telomere shortness precedes the onset of cardiovascular disease and diabetes. Early telomere attrition creates risk for early diseases of aging. However, once one has a chronic disease, many aspects of the disease process can promote accelerated telomere attrition. While there are a myriad of biochemical alterations in each disease, a common triad underlying many diseases of aging is oxidative stress, inflammation, and hyperglycemia/insulin resistance. Diabetes offers a clear example of how the disease process further shortens telomeres. ${ }^{15}$ Once one has diabetes, the impaired $\beta$ cell function and resulting higher levels of these biochemical stressors can further shorten telomeres.

This is also apparently the case for major psychiatric diseases. The presence of psychiatric disease is associated with shorter telomeres, particularly for major depression and anxiety disorders. There are dose-response relationships such that the longer the duration of the depression, the shorter the telomere length. ${ }^{16}$ It may also be that the short telomeres also preceded the onset of the condition, and longitudinal studies are needed to determine the strength of causal directions. Given the high comorbidity of medical and psychiatric conditions, it is important to take into consideration that the common condition of depression may alter aging biology, not just the physical disease condition.

\section{Disease treatments modulate telomere attrition}

Treatments for diseases may further affect the rate of telomere attrition, either speeding it up or slowing it down. Few studies have directly examined the effects of medications. Statins and possibly

This article is protected by copyright. All rights reserved. 
metformin may prevent telomere attrition. ${ }^{17}$ In contrast, highly active antiretroviral therapy in HIV appears to accelerate telomere attrition. Chemotherapy can work through telomere damage of both cancerous cells and healthy cells. ${ }^{18}$

While cell aging predicts disease, once one has disease, there is undoubtedly a clouded and complex picture, where both disease processes and aspects of treatment can further affect telomere stability and repair, and thus rate of attrition over time. There is a tremendous amount that could be easily learned by incorporating assessments of cellular aging, such as telomere length, into treatment studies.

\section{The bidirectional relationship between stress and HIV}

\section{Gretchen N. Neigh}

Individuals living with HIV are subject to a high stressor burden. This burden includes the influence of external stressors, such as financial burden and stigma, as well as the burden of the internal stressors of viral presence and antiretroviral medication. Evidence of the burden of these stressors is evident in the increased incidence of stress-related disorders among individuals living with HIV, such as depression and posttraumatic stress disorder. ${ }^{19}$ Furthermore, comorbidity of affective disorders with HIV affects overall longevity, as demonstrated by the report that women living with depression and HIV have higher mortality than euthymic women living with HIV. ${ }^{20}$

In order to understand how stressors and HIV may interact, it is important to visualize the relationship between stress and stressors. An organism's response to a stressor is the physiological state of stress, and stress is designed to return the organism to homeostasis. Similar to a rubber band being stretched, the relationship between stressors and stress is initially completely predictable and reversible. The force (stressor) is applied, and the stress response of the organism returns the system to homeostasis - the relationship is elastic or resilient. However, if the stressors are too great, the elasticity of the system begins to be compromised such that the force applied does not predictably generate the same response and the return to homeostasis may be incomplete or require shifts in function - the relationship is adaptable. If stressors are applied to an extreme point for a prolonged period of time, or if a genetic or environmental predisposition exists, then the response generated becomes maladaptiye. In the case of HIV, it is likely that the combined stressor burden shifts the relationship between stressors and the stress response to the point that a resilient response is less likely and adaptation is a more realistic goal for stress management.

This article is protected by copyright. All rights reserved. 
The stress response can be managed at both the psychosocial and biological levels.

Regardless of whether the origin of the stressor is psychosocial or biological, the initiated processes in the organism are virtually identical - that is, the hypothalamic-pituitary-adrenal (HPA) axis that facilitates the stress response does not differentiate between types of stressors. At the psychosocial level, interventions that reduce the impact of stressors, such as stigma, loss, or financial strain, can in part minimize the impact of HIV on the stress response system by preventing the initiation of a stress response. The biological response to stressors is also affected by HIV. This level of modulation has two primary points of intervention or titration: magnitude and duration. In terms of magnitude, both the cumulative burden of psychosocial stressors ${ }^{21}$ and the impact of viral proteins ${ }^{22}$ have been shown to alter the stress response.

Although the impact of HIV on the stress response is multifaceted, there are also multiple points of intervention. Psychosocial interventions are useful and important in the context of HIV. However, it is valuable to note that the stress-response system of individuals living with HIV is different than those without the disease, and it may be necessary to consider biological support for the HPA axis in order to allow the patient to reap the full benefits of a psychosocial intervention. In addition, it is vital to recognize that, while antiretroviral therapy is effective in reducing viral loads and restoring CD4 counts, these drugs are not without impact, and the influence of these compounds on P450 and other aspects of the stress response system can render patients more susceptible to the impact of stressors. ${ }^{23}$ Finally, given the ubiquitous nature of stress hormones, targeted end-organ interventions for the systems most affected in an individual demonstrating the repercussions of a cumulative stressor burden may be the most effective method of intervention for individuals aging with HIV.

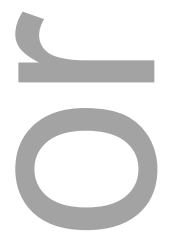

\section{From wasting to obesity: HIV and its therapy in aging}

\section{Kristine Erlandson}

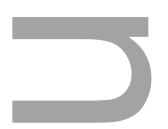

Some of the earliest manifestations of AIDS were the profound wasting observed with uncontrolled HIV infection, before the introduction of effective antiretroviral therapy. Similar to that of cancer

This article is protected by copyright. All rights reserved. 
cachexia, the wasting was multifactorial and due in part to nutritional deficiencies, increased resting energy expenditure, infections, cancers, and high levels of inflammation. The result was a significant loss in both muscle and fat. With the advent of effective antiretroviral therapy (ART), these weight changes could be partially reversed; however, the impact of HIV and ART on muscle and fat were far from over. Men with a history of wasting gained less weight over time and remained an average of nearly $10 \mathrm{~kg}$ less than men without a history of wasting. ${ }^{24}$ Importantly, this low muscle mass has been associated with increased mortality. ${ }^{25}$ Both ART and HIV were found to have toxic effects on the muscle, with many of the older nucleoside reverse transcriptase inhibitor (NRTI) therapies later implicated in mitochondrial toxicity. ${ }^{26} \mathrm{HIV}$-infected adults also have been shown to have gene expression patterns consistent with fibrosis and collagen deposition ${ }^{27}$ and to have greater fatty infiltration of the muscle and decreased strength with aging compared with HIV-uninfected controls. ${ }^{28}$

The early era of ART was quickly complicated by lipodystrophy, a constellation of changes in fat distribution, including both lipoatrophy, a loss of subcutaneous fat of the face and extremities, and lipohypertrophy, a gain in visceral, truncal, or dorsocervical fat. Older NRTI therapies have been most implicated in lipoatrophy, but there is evidence that all ART can contribute to lipohypertrophy. Even the newest ART regimens are associated with marked gains in fat, with some studies showing up to a $30 \%$ increase in visceral fat over just the first 2 years of treatment. ${ }^{29}$ The severity of lipodystrophy can range from very mild to quite severe and stigmatizing. Certain ARTs contribute to a variety of additional pathologies in fat that can become more pronounced in the setting of lipodystrophy, including mitochondrial toxicity and disruption in adipocyte differentiation. Additionally, the lipolysis that occurs in lipoatrophy is associated with an accumulation of free fatty acids, which ultimately may be deposited in visceral fat, muscle, or the liver. More recent data suggests that adipose tissue may actually serve as a reservoir for HIV virus, allowing for viral replication and further inflammation and subsequent adipose tissue dysfunction (reviewed in Ref. 30). The favorable weight changes among AIDS patients initiating ART were initially attributed to a return to health following a period of profound weight loss. Although the majority of HIV-infected adults now start on ART at much earlier stages, well before wasting, this weight gain has continued to occur. Thus, the problem of obesity, often overlapping with lipodystrophy, is now quite common. Regardless of the cause, the consequence of both obesity and HIV- or ART-attributed body fat changes are additive and result in increased insulin resistance, immune activation, and inflammation.

Changes in body composition resulting from HIV infection and complications of ART mimic those of normal aging, with facial atrophy, a loss of skeletal muscle mass, and accumulation of

This article is protected by copyright. All rights reserved. 
visceral and other ectopic fat. Furthermore, the combination of both low muscle mass and increased fat content (referred to as sarcopenic obesity) likely has a synergistic effect in HIV. ${ }^{25}$ These body composition changes are associated with changes in mitochondrial function and insulin resistance and both contribute to and are worsened by chronic inflammation. While newer ART will eliminate or minimize some of the insults seen early in the AIDS crisis, these changes contribute to comorbid disease development. Not unexpectedly, the result is what appears to be an earlier occurrence or worsened severity of many diseases of aging. Indeed, several cohorts have shown an earlier or more profound manifestation of many age-associated conditions, such as frailty, falls, fractures, cardiovascular disease, diabetes, cancers, and neurocognitive impairment, in HIV-infected adults.

With the body composition changes that many older, HIV-infected adults have experienced, the risk for age-associated diseases is often markedly underestimated. Prevention and treatment strategies for disease progression must target multiple pathways. Although we may not be able to eliminate the damage done with current ART, interventions targeted at muscle and fat have the potential to result in marked improvements in both the health span and life span.

\section{GDF11 and myostatin: new evidence for roles in aging}

\section{Marissa J. Schafer and Nathan K. LeBrasseur}

A central endeavor in geroscience research is to identify circulating mediators of biological aging. If such factors exist, harnessing or blocking their action may translate to enormous therapeutic potential. Until recently, growth differentiation factor 11 (GDF11) was believed to be a promising prorejuvenative protein that declines in the bloodstream throughout chronological aging. Therapeutic replenishment to youthful levels was demonstrated to restore regenerative capacity in muscle, heart, and brain (reviewed in Ref. 31).

GDF11 is remarkably homologous to myostatin (MSTN, also known as GDF8), differing in amino acid sequence within their mature domains by only 11 residues. GDF11 and MSTN also share canonical TGF- $\beta$ posttranslational processing and signaling, through binding to the activin type I or II receptors and subsequent activation of SMAD. In contrast to GDF11's purported progrowth effects, MSTN is a potent negative growth regulator, with blockade or loss of function resulting in skeletal

This article is protected by copyright. All rights reserved. 
muscle hypertrophy and hyperplasia. Accordingly, MSTN inhibition is a potential strategy to improve muscle-wasting conditions, including sarcopenia, cachexia, and frailty (reviewed in Ref. 32). Thus, a central question plagues the field: how can GDF11 and MSTN, doppelgängers in structure and signaling, exert antithetical functional effects?

New discoveries have begun to shed light on this issue, which include several studies challenging GDF11's antiaging, progrowth influence (reviewed in Refs. 33 and 34). A critical emerging experimental consideration is the requirement of detection methods that are able to resolve GDF11 from MSTN. The aptamer-based profiling platform that was employed in the studies implicating GDF11 in rejuvenative processes was unable to distinguish between GDF11 and MSTN. Similarly, cross-reactive antibody-based methods have been relied upon. The realization that these assays were insufficiently discerning has underscored the need for new detection methods (reviewed in Ref. 33). The most robust approaches are anticipated to leverage mass spectrometry (MS) for quantification of GDF11- and MSTN-based amino sequence differences. Moreover, methods integrating both immunoprecipitation and MS will be useful for determining the physiological contexts in which various forms of GDF11 and MSTN (latent versus mature) travel and their associations with regulatory proteins, such as follistatin, follistatin-like 3, and GDF-associated serum proteins (reviewed in Ref. 35). Indeed, these proteins likely play important context-dependent inhibitory or chaperone roles. Whether and how these complexes contribute to differing tissue targeting or activation of cognate receptors by GDF11 and MSTN, or changes in various states of health, aging, and disease, remain to be seen.

Explorations of circulatory dynamics may illuminate unknown local versus systemic activities. MSTN is expressed predominantly in skeletal muscle, and GDF11 is expressed more ubiquitously. Temporal considerations also appear to convey important functional differences. Mutation and expression patterns suggest that GDF11 is developmentally requisite, particularly for axial patterning, while MSTN wields antigrowth effects throughout development and adulthood. Furthermore, in humans, limited studies have interrogated associations between circulating GDF11 and MSTN abundance and clinically important health outcomes (e.g., physical, cardiovascular, or cognitive function). Such data will help substantiate the role of these proteins in aging and, ultimately, their therapeutic potential.

The questions that remain are reminiscent of a game of Clue. Which protein is it? In which tissue did it originate, and in which tissue is it exerting influence? Through which mechanisms (e.g., canonical activin receptor signaling, bound to regulatory proteins) is it acting? What are the GDF11-

This article is protected by copyright. All rights reserved. 
and MSTN-specific outcomes, and are these functions conserved in rodents and humans? Recent controversy emphasizes the need to utilize highly precise methods if we are to solve this mystery.

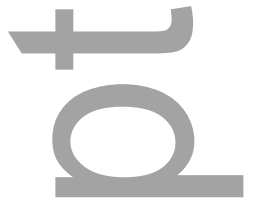

Mitochondrial dysfunction-associated senescence as a promoter of lipoatrophy in response to antiretroviral therapy

Christopher Wiley

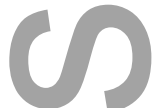

The advent of ARTs has held great promise for the treatment of HIV. These therapies lower viral load, preventing development of AIDS and, ultimately, delaying death. As a result of ART, individuals now regularly live decades after infection without developing life-threatening complications. Unfortunately, while treated individuals enjoy extended life spans relative to what they might without ART, patients now appear in the clinic with conditions that resemble premature aging_including cognitive impairment, cardiovascular disease, diabetes, osteoporosis, and lipodystrophy. ${ }^{36}$ The net effect of these various maladies is a reduced quality of life coupled to a shortened life span relative to uninfected individuals. These comorbidities suggest that one or more basic processes of aging is activated by either infection with HIV, the ART treatments that keep HIV in check, or both. While differentiating between these possibilities is challenging $\left(\mathrm{HIV}^{+}\right.$patients do not live long without ART, while $\mathrm{HIV}^{-}$people do not normally receive ART), murine and tissue culture models of ART treatment now suggest that these therapeutics activate one or more basic proaging processes.

What basic biological processes might promote aging in response to ART? Many ART drugs, including the nucleotide reverse transcriptase inhibitors (NRTIs), such as zidovudine and stavudine, ${ }^{37}$ and non-nucleoside reverse transcriptase inhibitors (NNRTIs), such as efavirenz, can interfere with normal mitochondrial function, and thus many have non-viral off-target effects. NRTIs are most commonly associated with mitochondrial dysfunction because they can inhibit mitochondrial DNA polymerase $\gamma$ (POLG), resulting in mitochondrial DNA depletion. Similarly, efavirenz inhibits complex I on the mitochondrial electron transport chain, lowering cellular energy (ATP) levels and increasing oxidative stress. ${ }^{38}$ Thus, many ART drugs can induce a state of mitochondrial dysfunction in otherwise healthy cells.

This article is protected by copyright. All rights reserved. 
How might ART-induced mitochondrial dysfunction drive age-related conditions? Both mitochondrial DNA depletion and inhibition of complex I induce cellular senescence, a state of essentially permanent mitotic arrest. ${ }^{39}$ This mitochondrial dysfunction-associated senescence (MiDAS) can drive age-related conditions via two mechanisms. First, the cellular arrest prevents senescent progenitor cells from repopulating a tissue. Second, MiDAS is accompanied by a senescence-associated secretory phenotype (SASP) that is distinct from other known inducers of cellular senescence. The MiDAS SASP consists of a mélange of biologically active molecules that can have potent effects on local tissues. For example, the MiDAS SASP inhibits the differentiation of adipocytes. Indeed, $P O L G$ mutant mice - which display profound lipoatrophy - accumulate senescent cells at a rapid rate. ${ }^{39}$ Lipoatrophy is also a common consequence of ART, and senescent cells appear in adipose tissue of patients that receive some NRTIs. ${ }^{2}$ Thus, senescent cells are somewhat of a "smoking gun" as an etiological agent for ART-induced lipoatrophy and possibly other age-related phenotypes.

Are senescent cells truly causal for age-related conditions associated with ART? Thus far, the evidence is largely correlative, with senescent cells appearing at the right places and times in conditions like ART-associated lipoatrophy. Fortunately, recent murine models in which senescent cells are selectively eliminated have shown that senescent cells indeed promote features of aging. ${ }^{40}$ These types of models hold promise both for determining whether senescent cells promote age-related conditions associated with ART and as a potential basis for novel therapeutic interventions aimed at eliminating senescent cells.

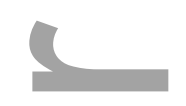

DNA methylation age is accelerated before AIDS-related non-Hodgkin lymphoma diagnosis Mary E. Seht

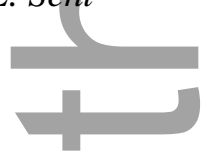

Diffuse large B cell lymphoma is the most common aggressive non-Hodgkin lymphoma in the United States, and its major risk factors include advancing age and immunosuppression. Markers of chronic $B$ cell activation are elevated in both normal aging and HIV infection and are associated with risk of developing AIDS-related non-Hodgkin lymphoma (AIDS-NHL). ${ }^{41}$ Aging and HIV infection lead to

This article is protected by copyright. All rights reserved. 
accumulation of immunosenecent cells and altered methylation of polycomb group target (PCGT) genes, which are involved in stem cell self-renewal, and whose methylation is aberrant in dysplasia and cancer. ${ }^{42}$ Acceleration of age-related methylation patterns involving CpGs from the PCGT pathway have been recently demonstrated in the setting of HIV -1 infection. ${ }^{43}$ The goal of our work is to characterize epigenetic patterns that are involved in aging, HIV infection, and lymphomagenesis.

The epigenetic clock, derived from 8000 samples from 82 Illumina DNA methylation and array data sets from 51 healthy tissues and cell types, allows one to estimate DNA methylation (DNAm) age of tissues, using methylation levels at $353 \mathrm{CpGs}$ from pathways involved in cell apoptosis and survival, self-renewal, and tissue development. ${ }^{44}$ DNAm age is highly correlated with chronologic age across tissues and species, correlates with cell passage number, is close to zero for embryonic stem cells and iPSCs, is highly heritable, and is applicable across species, and ageacceleration is seen in some cancer tissues. ${ }^{44}$ An online epigenetic age calculator is available for calculation of DNAm age based on data measured using the Illumina Infinium platform (450K or $27 \mathrm{~K}$ data) (https://labs.genetics.ucla.edu/horvath/dnadamage/).

In our study, we utilize peripheral blood mononuclear cells previously collected from participants at the Los Angeles site of the Multicenter AIDS Cohort Study (MACS). We analyze global methylation data from men who later developed AIDS-NHL at two time points (1-4 years and $>4$ years before diagnosis) and compare it to that of HIV-infected controls matched on $\mathrm{CD}^{+}{ }^{+} \mathrm{T}$ cell count and $\mathrm{HIV}^{-}$controls. We study participants from a broad age range (early 20 s to late $50 \mathrm{~s}$ ). Lymphoma subtypes in our study include Burkitt's lymphoma, diffuse large B cell lymphoma, and immunoblastic lymphoma.

Bisulfite sequencing experiments are performed in the UCLA Human Genetics Core Sequencing laboratory using the Illumina Infinium $450 \mathrm{~K}$ platform. We analyze global methylation data from peripheral blood mononuclear cells from MACS study participants and calculate DNAm age for each sample using the epigenetic clock. Preliminary results of our study confirm earlier studies showing that DNAm age is strongly correlated with chronologic age and that HIV-infection is associated with age acceleration in the epigenetic clock. Our laboratory is actively examining ageacceleration differences in samples from individuals who do and do not later develop lymphoma and comparing the degree of acceleration from visits closer to lymphoma diagnosis (1-4 years before) versus earlier time points ( $>4$ years before).

This article is protected by copyright. All rights reserved. 
Preliminary results confirm that DNAm age is accelerated in peripheral blood mononuclear cells in the setting of HIV infection, and suggest that DNAm age acceleration is increased in the years before AIDS-NHL diagnosis. We are well poised in our laboratory to further examine the relationship between global methylation changes and elevations in chronic inflammatory markers that occur before AIDS-NHL diagnosis.

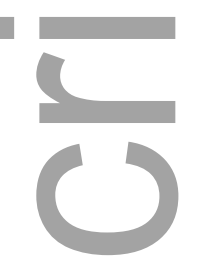

Metabolic microvascular dysfunction as a driver of organ aging Rosario Scalia and Satoru Eguchi

Leukocyte-endothelium interaction is a physiologic process necessary to avert development of infectious disease. In contrast to its beneficial role within the immunologic response and defense mechanisms, leukocyte trafficking appears to also be involved in the pathogenesis of organ tissue damage in chronic metabolic disorders. Indeed, increased leukocyte trafficking in response to hyperglycemia and insulin resistance has been linked with damage to blood vessels and surrounding tissue in diabetes, owing to the production of toxic mediators by activated leukocytes. ${ }^{45-47}$ Physiologically, phagocytic leukocytes perform most of their functions in the extravascular compartment. To reach this compartment, they must traverse the vascular endothelium. Therefore, interaction of circulating leukocytes with the vascular endothelium is a preliminary, essential step in the inflammatory response, and this event occurs on the venular side of the microcirculation. ${ }^{48}$ Leukocyte-endothelium interactions occur in three steps, each mediated by a specific set of cell adhesion molecules expressed on the endothelial cell surface: (1) leukocyte rolling (selectin family adhesion molecules (P-selectin, E-selectin)); (2) leukocyte adherence (immunoglobulin family adhesion molecules ICAM-1 and VCAM-1); and (3) leukocyte extravasation (ICAM-1 and PECAM1). Upregulation of cell adhesion molecules occurs in spontaneously hyperglycemic and obese mice. ${ }^{49,50}$ Circulating levels of soluble ICAM-1 and VCAM-1 are increased in diabetic and obese patients. ${ }^{51,52}$ Elevated ambient glucose causes increased leukocyte rolling and leukocyte adherence in cultured endothelial cell monolayers. ${ }^{53}$ It has also been observed that monocytes isolated from

This article is protected by copyright. All rights reserved. 
diabetic patients are more adhesive to cultured human endothelium than those obtained from normal subjects. ${ }^{54-56}$ Taken together, these data strongly indicate that a pathological inflammatory response characterized by enhanced endothelial adhesiveness and increased leukocyte-endothelium interactions occurs in the microvasculature during metabolic disorders. At the mechanistic level, loss of physiologic endothelial nitric oxide (eNO) appears to be correlated with the vascular inflammation of metabolic disorders. ${ }^{57,58} \mathrm{We}$ and others have demonstrated that loss of basal eNO levels in postcapillary venules rapidly induces inflammatory responses in the microcirculation, characterized by increased leukocyte-endothelium interactions and upregulation of endothelial cell adhesion molecules. ${ }^{59,60}$

This inflammatory microangiopathy is likely to be a key contributing factor to accelerated aging. Indeed, the aging vascular endothelium experiences a progressive loss of release of eNO, associated with endothelial dysfunction. ${ }^{61}$ Reduced release of NO in response to endotheliumdependent agonists has been demonstrated in aged arteries, including the brachial artery ${ }^{62}$ and coronary artery ${ }^{63}$ in humans and the aorta, ${ }^{64}$ carotid artery, ${ }^{65}$ and mesenteric artery ${ }^{66}$ in rats. The mechanism responsible for this age-related endothelial dysfunction has not yet been clearly elucidated, but it might involve (1) changes in expression/and or coupling of eNOS, ${ }^{67-69}$ (2) increased breakdown of eNO due to an augmented production of superoxide anions, ${ }^{70,71}$ or (3) a gradual loss of antioxidant capacity that normally provides cellular protection against reactive oxygen species. ${ }^{72,73}$ The loss of physiologic eNO with aging appears to also be correlated with vascular inflammation. Thus, aging is associated with enhanced expression of adhesion molecules in the rat aorta ${ }^{74}$ and increased adhesion of monocytes to the endothelial cell surface in the rabbit aorta. ${ }^{75}$ Remarkably, serum-soluble levels of ICAM-1 and other adhesion molecules are also elevated with aging in humans. ${ }^{76}$ Endothelial dysfunction and inflammatory phenotypes in the aging vasculature have been linked to damage of large conduit vessels. Studies in aging laboratory animals have demonstrated that reduced eNOS levels, associated with vascular inflammation, cause apoptosis of coronary endothelial cells $\mathrm{s}^{77,78}$ and accumulation of atherogenic glycosaminoglycans at the arterial wall. ${ }^{75} \mathrm{We}$ have reported the occurrence of increased leukocyte-endothelium interactions in the aging F1-F344xBN rat. ${ }^{79}$ The importance of this research is underscored by the fact that, in humans, the incidence of coronary artery disease, ${ }^{80,81}$ hypertension, ${ }^{82}$ and congestive heart failure ${ }^{83,84}$ greatly increases with aging, independent of other risk factors. Thus, full understanding of the cellular mechanisms by which metabolic disorders cause alteration in microvascular function is likely to shed new light on the relationship between metabolic disorders and aging.

This article is protected by copyright. All rights reserved. 


\section{$+$ \\ How does diabetes affect the seven pillars of aging in the kidney? \\ Balakuntalam S. Kasinath}

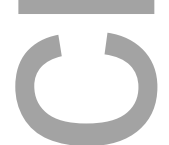

Older age is a risk factor for end-stage kidney disease, the most common cause of which is diabetes. Conversely, diabetes induces senescence in the kidney independent of age. ${ }^{85}$ Thus, there is a mutually reinforcing interaction between diabetes and aging in kidney injury that merits further investigation. Diabetes causes glomerulosclerosis, tubulointerstitial fibrosis, and vascular disease, leading to progressive loss of kidney waste-clearance function. Aging is also associated with similar histologic lesions in the kidney (nephrosclerosis); in addition, ischemic changes and glomerular collapse may be seen. Here, I review the scant information that is available on the interaction between diabetes and aging in the context of the pillars of aging. In most of the categories below, diabetes and aging have been separately studied; however, their interplay has not been explored in depth.

Diabetes is associated with increased oxidative stress in the kidney that is augmented by aging. ${ }^{86}$ Aging appears to stimulate mitochondrial generation of reactive oxygen species in the kidney, ${ }^{87}$ whereas this may not be the case in diabetes. ${ }^{88}$ Clinical observations show that, in the presence of pre-existing kidney disease, diabetes and aging are risk factors for ischemic stress-induced injury to the kidney. How aging and diabetes interact in the kidney's response to the aforementioned stress factors remains to be explored.

In both diabetes and aging, monocyte infiltration is commonly seen in the kidney. Kidney cell nuclear localization of NF- $\mathrm{kB}$, a master regulator of cytokine expression, is increased in aging rodents. ${ }^{89}$ Exuberant inflammatory response appears to contribute to the demise of type 2 diabetic mice. The life span of $d b / d b$ mice with type 2 diabetes is about 1 year, significantly less than that of nondiabetic mice; while tumors are the main cause of death in nondiabetic mice, we observed that suppurative inflammation is the main cause of fatality in $d b / d b$ diabetic mice. ${ }^{90}$ Thus, diabetes shortens the life span and changes the cause of death in mice. Diabetes also appears to change the type of tumors that occur in aging $d b / d b$ mice. ${ }^{90}$ More work is needed to explore the kidney's adaptation to inflammation and infection in aging diabetic mice.

This article is protected by copyright. All rights reserved. 
Both aging and diabetes are associated with endoplasmic reticulum stress in the kidney. Impaired autophagy contributes to kidney injury in diabetes. ${ }^{91}$ Impaired renal autophagy also occurs in aging, probably due to Sirt1 deficiency. ${ }^{92}$ Whether aging and diabetes together augment autophagy impairment accelerating kidney injury requires investigation. Although ER stress inhibits general protein synthesis, synthesis of specific proteins, including matrix proteins, appears not to be inhibited, contributing to kidney fibrosis in both of these conditions. A new related development is that endogenous hydrogen sulfide regulates protein synthesis in the kidney. Hydrogen sulfide content in the kidney is reduced in diabetes; sodium hydrosulfide, a source of hydrogen sulfide, ameliorates kidney injury in diabetic rodents. ${ }^{93}$ Hydrogen sulfide inhibits high glucose-induced protein synthesis in renal cells in vitro by stimulating AMP-activated protein kinase, which leads to inhibition of mTOR. ${ }^{94}$ We have observed that the kidney hydrogen sulfide content is reduced in aging mice (unpublished data). Whether administration of hydrogen sulfide ameliorates aging-induced kidney injury is unknown. Whereas rapamycin, an inhibitor of mTOR, prolongs life span in nondiabetic mice, it augments mortality in $d b / d b$ diabetic mice $;^{90}$ the mechanistic basis of this differential response requires future exploration. Hydrogen sulfide has been reported to mediate dietary restriction-induced protection of the kidney against ischemic injury and extension of life span in worms and yeast. ${ }^{95}$

Infusion of early endothelial outgrowth cells seems to improve senescence, induce autophagy, and ameliorate kidney injury in diabetic mice. ${ }^{96}$ Infusion of bone marrow cells from young mice ameliorates senescent changes in the kidney in old mice. ${ }^{97}$ Whether stem cells aid in ameliorating kidney damage in aging diabetic mice needs to be investigated.

DNA damage occurs in the kidney in diabetes and aging. Recent reports indicate that epigenetic acetylation markers are increased within genes related to inflammation in peripheral blood monocytes from diabetic patients with renal and retinal damage. ${ }^{98}$ Epigenetic mechanisms in the aging kidney are not well understood.

In summary, the interaction of diabetes and aging in the kidney may occur by the potentiation of the same mechanistic pathways or by recruitment of different pathways that lead to the same phenotype. With rising life span and increasing prevalence of diabetes, it is very likely that we will have to contend with increasing numbers of older adults with diabetic kidney disease. Meaningful intervention to reduce morbidity and mortality in this population requires better understanding of the underlying mechanisms.

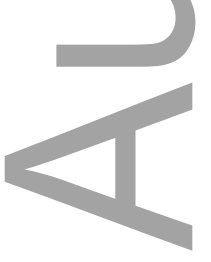

This article is protected by copyright. All rights reserved. 


\section{Does diabetes accelerate aging of $\beta$ cells through hyperglycemia (glucose toxicity) and also insulin resistance?}

Jeffrey B. Halter

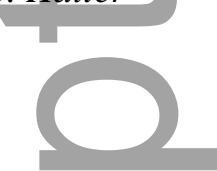

A consistent decline of $\beta$ cell function and insulin secretion is a hallmark of aging, as demonstrated in rodents and humans. ${ }^{99}$ Aging effects include a decline of both pancreatic islet cell proliferation and $\beta$ cell turnover. ${ }^{100,101}$ The decline in islet proliferative capacity with age in normal mice is modest.

However, this aging effect is much more dramatic when the proliferative response of older animals to partial pancreatectomy, streptozotocin, and exendin-4 (a GLP-1 agonist) is compared with the robust responses observed in young animals. ${ }^{101}$ Similarly, young mice are able to increase islet mass and $\beta$ cell proliferation in response to high-fat diet, but older mice cannot. ${ }^{102}$ Thus, loss of islet proliferative capacity appears to occur early in life in rodents. Exposure to high concentrations of glucose in vitro can lead to apoptosis of $\beta$ cells, evidence of glucose toxicity. ${ }^{99}$ Islets from older Sprague Dawley rats appear to be more sensitive to glucose-induced apoptosis. ${ }^{100}$

Pancreatic $\beta$ cell proliferation appears to be dependent on cell cycle regulation. There is a substantial increase in expression of the cell cycle regulator p16 in islet tissue from older mice who demonstrate the age-related decline in islet proliferation. Overexpression of p16 markedly reduces islet proliferation in younger mice to a level similar to that observed in older mice, and knockout of p16, preventing p16 from increasing with aging, appears to reverse the age-related decline of islet cell proliferation in this model. ${ }^{103}$ Furthermore, p16 is one of the proteins produced from the CDKN2a locus. Genetic variation at this locus has emerged as a consistent association with type 2 diabetes risk from genome-wide scanning studies in humans.

Findings from humans parallel age-related changes observed in rodents, including diminished insulin secretion in vitro and in vivo, diminished proliferative capacity, and increased sensitivity to the apoptotic effects of high glucose exposure. ${ }^{99}$

A conceptual model for the interaction of aging and diabetes is provided in Figure 2. In the setting of the age-related impairment of $\beta$ cell function, there is a maladaptive response to lifestyle-related insulin resistance, leading to more impaired insulin secretion and progression to impaired glucose tolerance (prediabetes) and type 2 diabetes. Glucose toxicity from chronic exposure to hyperglycemia, in turn, can contribute directly to insulin resistance and to further impairment of pancreatic $\beta$ cell

This article is protected by copyright. All rights reserved. 
function. In this way, hyperglycemia of diabetes may drive further worsening of $\beta$ cell function and proliferation associated with aging.

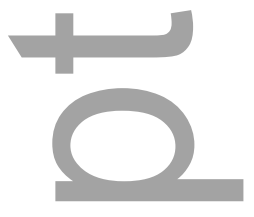

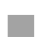

\section{How does activation of inflammatory and coagulation pathways in cancer patients affect survivorship and functional status?}

Harvey Jay Cohen

There is a strong epidemiologic association between markers of inflammation and activation of the coagulation system with functional decline and survival in non-cancer-bearing older adults, which are predictive of subsequent decline. ${ }^{105}$ Moreover, cancer also induces activation of these two systems, and inflammation has been included as one of the hallmarks of both cancer and aging. ${ }^{106,107}$ Thus, a potentially vicious cycle exists in a patient with cancer such that aging might affect the progress of cancer development and that cancer might affect the process of aging simultaneously. Moreover, the introduction of cancer treatments might also accelerate the latter process. Figure 3 indicates possible pathways involved and how they might affect survival and function.

Thus, inflammation may be initiated in cancer patients by the increased numbers of neutrophils and their activation, which can produce increased adhesion and release of free radicals; simultaneously, predominantly via the NF-kB pathway, there is increased IL-6, VCAM, IL-1 $\beta$ and TNF- $\alpha$ produced. Concomitantly, coagulation is activated by tissue factor (TF) release, and the procoagulant state produces D-dimers and fibrin crosslinking. Endothelial activation occurs, indicated by increased VCAM, adhesion, and reactive oxygen species. There is direct interplay between these two systems, as D-dimers can increase synthesis and release of IL-1 $\beta$ and PAI-1 from macrophages in vitro and TF can induce production of NF-kB, IL-6, and VCAM. ${ }^{108}$ Thus, this is essentially one interconnected system. Treatment can likewise activate these pathways, in part via free radical generation, especially for chemotherapy and radiation therapy. The impact of immunotherapy is not clear, although checkpoint inhibitors release immune system inhibition with toxic effects on the host acutely, but the long-term impact is unknown. Treatment can directly affect organ function as well

This article is protected by copyright. All rights reserved. 
(e.g., anthracycline effect on the heart). Cancer can also result in an increase in p16 and decreased telomere length, which may lead to an increase in senescent cells and further release of inflammatory factors, as discussed by Campisi.

The impact of these pathway activations results in organ and vascular damage. For example, IL-6 and other inflammatory factors induce the cachexia syndrome; in animal models, fatigue, weakness and cognitive decline are produced by injection of inflammatory cytokines; IL-6 produces muscle wasting and bone loss in experimental animals; atherosclerosis, another pathway to fatigue and weakness, is induced; GFR is reduced, and inflammation suppresses bone marrow function, resulting in anemia. The cumulative effect of such organ damage can produce a chronic multiple organ dysfunction syndrome (CMODS), a chronic analogy of what is frequently seen in intensive care units in conditions like sepsis, which similarly but acutely activate the inflammatory and coagulation systems. ${ }^{109}$ The CMODS might then produce a premature aging or frailty phenotype resulting in decreased function and shorter survival. ${ }^{110}$

Questions still to be answered include (1) whether we can establish further direct experimental evidence that cancer-related inflammation/coagulation activation produces organ damage, (2) whether there are common mediators across organ systems or unique ones for each, and (3) whether these pathways are targetable to improve function and survivorship as people age.

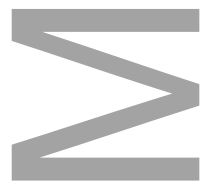

\section{Which animal and/or cellular models are best for studying the effects of cancer and cancer therapy on the aging process?}

Judith Campisi

A relatively underappreciated effect of many malignant tumors is their ability to cause genomic damage or damage responses in distal tissues. ${ }^{111}$ More generally, paraneoplastic syndromessymptoms that are due to cancer but not to the local presence of cancer cells-have been known for decades. ${ }^{12}$ In both cases, the ability of tumors to affect distal tissues is thought to derive from circulating tumor-derived cytokines, hormones, and other factors. Notably, the indirect effects of cancers-which include neurological deficits, thrombocytosis, anemia, glomerulonephritis, and other

This article is protected by copyright. All rights reserved. 
symptoms - partially overlap with phenotypes and pathologies that are common among non-diseased elderly. Thus, cancer, a major age-related disease itself, can also drive the development of noncancer pathologies associated with aging.

Related to drivers of aging phenotypes and pathologies are many of the cytotoxic and genotoxic therapies that are commonly used to treat cancer. Recent studies show that children who were successfully treated for leukemia or lymphoma and are now middle-aged adults suffer from a host of age-related diseases that are characteristic of much older individuals. ${ }^{113}$

Many anticancer therapies are potent inducers of cellular senescence, a tumor-suppressive stress response that entails an irreversible arrest of cell proliferation and development of a complex SASP that includes a host of inflammatory cytokines, chemokines, growth factors, and proteases. ${ }^{114}$ Senescent cells accumulate with age in many mammalian tissues, and many anticancer therapies result in a long-term burden of senescent cells. The persistent presence of senescent cells, and especially the proinflammatory SASP, are thought to be significant drivers of numerous age-related diseases. ${ }^{115}$

Recently, transgenic mouse models have been developed in which it is possible to selectively eliminate senescent cells. These models show that senescent cells are responsible for a number of adverse phenotypes caused by anticancer therapies. These adverse phenotypes include the development of cancer metastases, cardiotoxicity (which often limits the use of these therapies), loss of hemostasis, and loss of robust physical activity - phenotypes and pathologies that also increase during aging.

Many questions remain unanswered regarding how cancer and its treatments can drive aging. For example, both tumors and the senescent cells induced by cytotoxic/genotoxic therapies secrete many molecules that are proinflammatory immune activators. Very little is known about which of these secreted factors are most important for activating the immune system, which immune components are most important for the proaging responses, and whether the secreted factors can drive aging phenotypes independent of the immune system. Likewise, little is known about which distal tissues are most affected by tumors, which tissues accumulate the most senescent cells after anticancer therapies, and which tissues are most important for the resulting aging phenotypes and pathologies.

What types of interventions might be developed to alleviate the effects of tumors and anticancer therapies on age-related phenotypes and pathologies? Once specific SASP factors are

This article is protected by copyright. All rights reserved. 
identified as significant drivers, is should be possible to develop therapies to neutralize them or their targets. However, given the complexity of the secretomes of tumors and the SASP ${ }^{114}$ the proaging effects might be caused by multiple factors, thus diminishing the efficacy of single-agent interventions. As the regulatory pathways that activate and maintain tumor secretomes and the SASP are identified, strategies can be developed to prevent the development of this phenotype by specifically targeting these pathways. For example, much of the SASP is controlled by p38MAPK and NF- $\mathrm{KB},{ }^{116}$ for which inhibitory drugs have already been developed. A disadvantage of this approach is that it requires the continuous presence of the inhibitory drugs, increasing the risk of adverse side effects. A third strategy is to develop drugs that can selectively eliminate senescent cells, similar to the effects of the transgene in the mouse models. At least one such drug (ABT-263) was recently identified, ${ }^{117}$ although additional effort will be need to optimize this drug and/or develop alternatives.

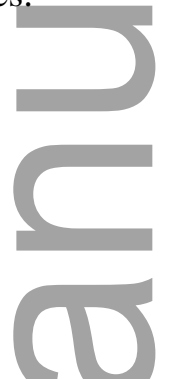

Functional decline in the older cancer patient: can lifestyle interventions turn back the hands of time? And if so, through what mechanism?

Wendy Demark-Wahnefried

The number of caneer survivors in this country is expanding rapidly, given converging trends toward aging and improvements in early detection and treatment. In 2014, there were roughly 14.5 million survivors in the United States, and projections indicate that this number will approach 19 million by $2024{ }^{118}$ This patient population provides an optimal model to study aging, not only because of rising numbers of survivors and the fact that most (61\%) are age 65 and older, ${ }^{118}$ but more importantly because decades of research evidence shows that the process of aging appears to speed up once the cancer diagnosis is rendered.

An example of accelerated aging is provided by longitudinal research on body composition that measures change in lean and fat mass after diagnosis (Fig. 4). ${ }^{119}$ Studies initiated in the 1990s among breast cancer patients receiving adjuvant chemotherapy show significant increases in adiposity

This article is protected by copyright. All rights reserved. 
and concurrent losses in muscle in the year following diagnosis. The changes in body composition that these patients undergo in 1 year are comparable to 10 years of normal aging. These results have been replicated time and again among breast cancer patients, as well as those with other forms of cancer. ${ }^{120}$ The increase in fat mass most likely contributes to a hyperinflammatory state among these survivors, and the decrease in muscle mass may be an underlying cause of the accelerated decline in physical functioning experienced by these cancer survivors - declines that affect the ability to work, perform activities of daily living, and live independently. ${ }^{121}$ Moreover, it is hypothesized that the decreases in body protein detected by fairly imprecise methods, such as dual X-ray absorptiometry, are also likely to manifest in changes in levels of circulating binding proteins, hormones, and other key constituents that are involved in aging, such as DNA repair, immune response, and mitochondrial integrity. Cancer and its many forms of treatment are also likely to influence the microbiome, as well as to induce a broad landscape of epigenetic changes that regulate aging.

While previous studies show that some individuals are either resistant and do not succumb to these common cancer- or treatment-induced adverse effects or are resilient and able to bounce back from such adversity, the predictors that portend future health span are currently unknown. Therefore, an opportunity to gain insights into the mechanisms of aging exists through the longitudinal study of these populations.

Another research opportunity that may inform aging research lies in studying the response of cancer survivors to interventions. A healthy lifestyle may be important in restoring body composition and functioning to baseline levels. A handful of studies promoting physical activity and a healthful diet and body weight have been conducted to determine if the trajectory of functional decline among cancer survivors can be hindered or reversed. To date, the largest study was the Reach-out to ENhancE Wellness (RENEW) in Older Cancer Survivors trial, a two-arm randomized controlled trial among 641 older (age 65+) overweight or obese survivors of breast, prostate, or colorectal cancer in the United States, Canada, and the United Kingdom. ${ }^{122}$ The intervention, which promoted a slow rate of weight loss, a plant-based diet, and resistance and endurance exercise via telephone counseling and tailored, mailed print materials, effectively slowed declines in physical functioning compared to waitlisted controls. Secondary analyses showed that survivors who were most likely to benefit from the intervention were those with fewer comorbidities who either were not as obese at baseline or lost greater amounts of weight over the study period. Other lifestyle interventions in this patient population also show improvements in physical function or performance with concomitant reductions in biomarkers associated with inflammation (e.g., IL-6, IL-8, C-reactive 
protein) and energy metabolism (e.g., insulin, c-peptide), with preliminary data gathering on telomerase. Therefore, studying the response to lifestyle interventions, as well as interventions that may be more intensive in this patient population, may also provide insights not only into the molecular and cellular mechanisms that cause accelerated aging, but to solutions that may potentially turn back the hands of time.

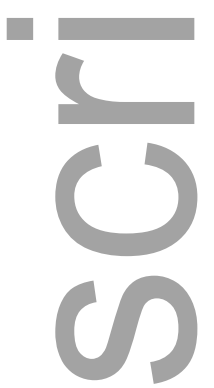

\section{How does cancer treatment affect cognitive aging?}

Tim A. Ahles

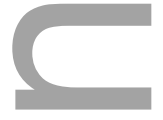

Cancer treatments, including chemotherapy and radiation, endocrine, and immune therapies, can cause long-term alterations in cognitive function among a subgroup of vulnerable patients. Risk factors for posttreatment decline are similar to factors that influence normal cognitive aging, including age, cognitive reserve, genetic factors (apolipoprotein E, catechol- $O$-methyltransferase, and brainderived neurotrophic factor), comorbid conditions, and frailty. ${ }^{123}$ Cancer treatments can have effects on specific brain structure and function. However, cancer treatments also affect multiple systems associated with the biology of aging, including causing (1) DNA damage, (2) chronic inflammation, (3) cell senescence, (4) oxidative stress, (5) depletion of stem cell reserve, and (6) shortening of telomeres. ${ }^{123}$ Recent research has demonstrated activation of pathways associated with aging, such as increased expression of p16INKa and ARF in breast cancer patients treated with chemotherapy ${ }^{124}$ and activation of ERK and AKT signaling pathways in a rat model of chemotherapy-induced cognitive change. ${ }^{125}$ Further, cancer treatment affects brain structure and function associated with the aging brain, including volume reduction and decreases in activation, white matter integrity, vascularization, and neurotransmitter activity. ${ }^{123}$

Taken together, the above findings suggest that cancer treatments interact with and may accelerate cognitive aging through affecting a broad array of biological systems associated with aging. Accommodation of specific and systemic effects of cancer treatment on cognitive aging requires

This article is protected by copyright. All rights reserved. 
utilization of broad-based systems theories of aging. Network/engineering/redundancy theories of aging posit that complex biological systems have evolved highly redundant systems that create resiliency through tolerance to local system failure. ${ }^{126}$ However, redundancy also leads to damage accumulation, particularly if repair mechanisms are not optimal. Since the brain has limited capacity for repair, damage accumulation is particularly problematic. Therefore, multiple patterns of failure can lead to increased vulnerability to cognitive aging through effecting specific systems and/or increasing random error/failure. Sophisticated mathematical models based on graph theory are being developed that simulate activity within complex biological systems, including the brain. ${ }^{126}$ An advantage of these models is that patterns of failure rate can be simulated to examine the impact on the system, thereby generating hypotheses that can be tested in human and animal studies. Consequently, mathematical models of complex systems may be an important future addition to translational research efforts examining the interface of cognitive aging and cancer treatments.

The network biology approach described above suggests the need to evaluate resiliency across multiple biological systems. Allostatic load refers to cumulative physiological dysregulation related to a lifetime of adapting to exposure to physiological and psychological demands. ${ }^{127}$ Accumulation of allostatic load occurs when adaptive responses to challenges chronically fall outside the normal operating range, resulting in wear and tear on the multiple components of the regulatory system. Consistent with network theories, these physiological and psychological challenges can increase failure accumulation across biological systems, resulting in decreased resiliency. Measurement of allostatic load is operationalized as the assessment of biological parameters related to risk of disease across several biological systems, including the HPA axis, sympathetic nervous system, immune system, cardiovascular system, and metabolic processes. To date, numerous studies have demonstrated that high levels of allostatic load are associated with risk of mortality, development of specific diseases and frailty, and cognitive decline associated with aging. Allostatic load captures the combined effect of multiple biological systems that have individually been found to predict age-related cognitive decline. ${ }^{127}$

Unanswered questions for future research include (1) which models that describe the resiliency and failure of complex systems are most appropriate for guiding research related to interactions of aging processes, cancer, and cancer treatments in determining cognitive aging? (2) what panel of biomarkers across biological systems best captures system resiliency and vulnerability? and (3) which advanced statistical models hold potential for understanding how brain structure and

This article is protected by copyright. All rights reserved. 
function change with aging and in response to insults to the brain caused by cancer and cancer treatments?

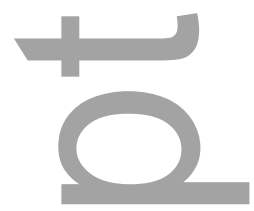

\section{Which mechanisms do or do not drive aging in diabetics?}

Nir Barzilai

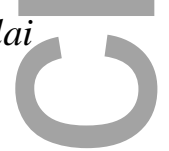

Diabetes is considered a model for accelerated aging. It is imperative, though, to seek the pathology that commonly exists in the elderly and then determine if it is accelerated with diabetes. For example, although macrovascular diseases are common in the elderly, recent study suggests that CVD mortality and all mortality are not accelerated; in fact, they are decelerated in elderly over the age of 75 who have diabetes. ${ }^{128}$ Severe microvascular complications of diabetes - proliferative retinopathy, peripheral and autonomic neuropathy, and end stage (Kimelstein-Wilson kidney) nephropathy — do not appear in the non-diabetic elderly and have been demonstrated to be mainly the consequence of hyperglycemia rather than aging. Insulin resistance is hallmark of aging and type 2 diabetes mellitus (T2DM). Yet insulin resistance is also a stress response and is part of adaptive/protective response to deal with extra nutrients. In fact, in animal models there is no centrality to insulin sensitivity in predicting life span. ${ }^{129}$ There are numerous models of insulin resistance models that live significantly longer; treatment with rapamycin is an example. There are also numerous models with enhanced insulin sensitivity with normal or shorter life span; protein tyrosine phosphatase, non-receptor type 1 (Ptpn1) knockout mice is an example of an insulin-sensitive model with a significantly decreased life span.

The progress in aging has been accelerated by studying models that have extended health and life spans. Interestingly, studies have determined that commonly used antidiabetic drugs, such as metformin ${ }^{130}$ and acarbose, ${ }^{131}$ may extend health span and life span in animals. In human studies, in addition to prevention of T2DM, metformin also prevents cardiovascular diseases ${ }^{132}$ and is associated with less cancer ${ }^{133}$ in T2DM. Furthermore, elderly individuals over 70 years of age with T2DM treated with metformin have significantly less mortality than non-diabetic subjects with less diseases and obesity. ${ }^{134}$ Acarbose not only prevented T2DM but also achieved a $\sim 50 \%$ reduction in 
cardiovascular end points in prediabetic subjects. ${ }^{135}$ Metformin has multiple aging-relevant actions at the cellular and organismal levels, including activation of AMP-activated kinase (AMPK), decreased insulin levels, decreased insulin/insulin-like growth factor-1 (IGF-1) signaling, inhibition of mTOR, inhibition of mitochondrial complex I in the electron transport chain, and reduction of endogenous production of reactive oxygen species (ROS), but whether it is a superdrug or whether one or more mechanism retards aging is unclear. Similarly, while acarbose, an $\alpha$-glucosidase inhibitor, is largely unabsorbed in the intestine and slows the absorption of glucose; its antidiabetic mechanism is probably not the same mechanism responsible for longevity because correcting glucose by other treatments is not associated with similar outcomes. Therefore, understanding drug mechanisms of action provides insight for both elderly and diabetic patients to increase translation and intervention for the development of the next generation of treatments.

Metabolism is also controlled by hypothalamic neuron circuits that affect peripheral metabolism. Insulin, leptin, and nutrients administered next to or into the hypothalamus can modulate insulin action in the periphery. Some of those circuits fail in aging; however, administration of IGF-1 seems to restore them. Indeed, insulin or IGF-1 actions in the brain are extended to other organs and are associated with Alzheimer's disease (AD), ${ }^{136}$ which may have significance for treatment of metabolic and cognitive diseases.

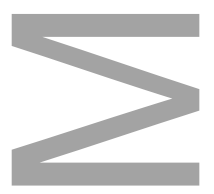

\section{Understanding and mitigating premature aging due to cancer and chemotherapy} Arti Hurria

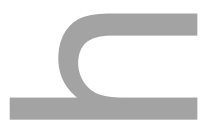

The hallmarks of aging can be utilized as a framework with which to understand the impact of cancer therapies on the aging trajectory. The primary mechanisms of action of several cancer treatments affect specific hallmarks of aging, such as genomic instability, cellular senescence, and stem cell exhaustion. ${ }^{137}$ Furthermore, the primary impact of cancer itself on the patient can accelerate the aging process. Hence, cancer and cancer therapy places patients at risk for a premature aging syndrome, thus serving as a potential human model to understand the aging process.

This article is protected by copyright. All rights reserved. 
Receipt of chemotherapy is a physiologic stressor, which unmasks an individual's physiologic reserve. Some patients are able to tolerate treatment without undue side effects, while others experience major side effects that limit the ability to deliver treatment. Cancer and cancer treatment can create symptoms consistent with the frailty phenotype described by Fried and colleagues, including slowness, weakness, weight loss, low activity, and fatigue. When a patient completes the chemotherapy course (if no further treatment is required), the patient will recover; however, this rate of recovery is variable. Hence, the receipt of treatment can be considered a human model of accelerated aging brought on by a physiologic stressor, and, when the stressor is withdrawn, there is opportunity to study the individuals' resilience (i.e., their ability to bounce back to their prior level of functioning).

Although patients recover upon completion of chemotherapy, there is concern in the cancer literature that we have placed patients on an accelerated aging trajectory. This hypothesis is supported by data collected from cancer survivors who report poorer physical function, ${ }^{138-140}$ poorer quality of life, ${ }^{141,142}$ and increased number of comorbidities, ${ }^{143,144}$ as well as risk for cognitive decline. ${ }^{145,146}$ The underlying cancer treatment may affect telomere length, ${ }^{147-150}$ increase p16 expression, ${ }^{151}$ increase proinflammatory cytokines, ${ }^{152,153}$ and increase resting energy expenditure. ${ }^{154,155}$

There are several unanswered questions. How does cancer treatment affect the aging trajectory? Are patients who receive cancer treatment on a different trajectory of aging that parallels normal aging (the phase-shift hypothesis) or are they now on an accelerated aging trajectory where functional decline is accelerated in comparison to normal aging (the accelerated-aging hypothesis). Are these changes reversible and, if so, what interventions are needed in order to reset to a normal aging trajectory? How does aging affect cancer biology and progression? How can cancer and cancer therapy be used to further our understanding of the molecular pillars of aging? All of these questions are important research directions that can not only inform the risks and benefits of cancer therapy, but also be utilized as a model to understand human aging and resilience.

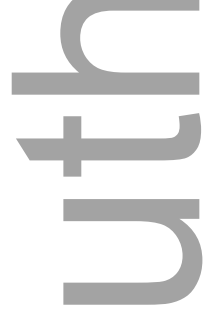

The gut barrier, microbiome, and health in HIV and aging

This article is protected by copyright. All rights reserved. 


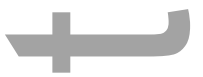

Common features of aging in both animal models and humans - including models of accentuated aging, like HIV infection - include breakdown in gut barrier function and dysbiosis of the gut microbiome. Indeed, in the very earliest stages of HIV infection, gut epithelial barrier function is impaired by breakdown of tight junctions between epithelial cells, increased epithelial cell apoptosis, and loss of mucosal immunity. These defects allow for translocation of microbial products into the systemic circulation and a chronic inflammatory state. ${ }^{156}$ Markers of gut epithelial barrier dysfunction in HIV strongly predict increased mortality, even after suppression of viral replication is achieved with antiretroviral therapy, ${ }^{157}$ suggesting that these defects might plausibly play a role in driving disease. Similarly, gut barrier defects are commonly observed with aging in several different species, from Drosophila to baboons and humans. ${ }^{158-160}$ While the specific mechanistic pathways that drive these gut barrier defects may differ between species and model system, the resultant systemic inflammatory state from microbial translocation may well contribute to several end-organ complications and an accentuated aging phenotype. Dysbiosis of the gut microbiome also occurs in both HIV infection and aging and may contribute to systemic pathology, not simply through increased microbial translocation, but also via the pathologic metabolic products that they produce. Some of these products, such as those of the kynurenine pathway of tryptophan catabolism, may have a multitude of deleterious effects on the immune system, the nervous system, and even mental health. ${ }^{161,162}$ These mechanistic similarities between HIV and aging provide multiple potential therapeutic targets to improve the health span in each setting. That said, the degree to which dysbiosis and microbial translocation are causes or consequences of the inflammatory state in both HIV infection and aging remains unclear. While animal model data suggest a potential causal role of dysbiosis and microbial translocation in contributing to multimorbidity and mortality, ${ }^{158}$ targeted clinical trials are needed in humans to prove causality in both the HIV and aging fields. It also needs to be recognized that, just as the specific underlying mechanisms leading to dysbiosis and microbial translocation in HIV and aging may differ, the optimal strategies for therapeutic interventions may also differ. Nevertheless, recognizing the mechanistic similarities between HIV and aging may help prioritize interventional targets to pursue and accelerate our understanding of each condition as these research agendas proceed in parallel.

This article is protected by copyright. All rights reserved. 


\section{Conclusions and recommendations}

The Second Geroscience Summit, exploring disease drivers of aging, brought together a broad range of scientists to diseuss issues relevant to basic biology of aging, translation and clinical practice. In addition to the scientific presentations, briefly described in the text, many additional participants contributed vigorously to the discussions.

Perhaps the most relevant conclusion from the discussions is that geroscience is probably the best platform to address the complex interactions between aging and chronic diseases, not solely as stated in the original concept (aging is the major risk factor for diseases), but also as a two-way street, where diseases also accelerate the pace of aging. Equally important is the growing realization that health is more than the absence of disease, and, thus, when an individual is affected by a major disease, the work of the health provider is not done, since even if the disease is eradicated, full health is often not yet fully restored. In this context, the possibility of using "anti-aging" approaches as coadjuvants in disease fighting emerges as an exciting and promising alternative. Of course, much work remains to be done in order to arrive at that end, including the identification of biomarkers for the different pillars of aging and further characterization of the individual pillars most directly affected by the disease and/or the treatment. In that context, it is useful to remember that, while the pillars of aging are often discussed as independent entities, it is well accepted that changes in any of them often affect the other pillars. In that manner, it is possible to conclude that a given disease/treatment pair affects all the pillars of aging, which complicates future studies and decisions concerning possible therapeutic approaches. Thus, it is crucial to carefully dissect which pillars of aging are affected directly, earlier, and/or the most. In addition, every individual is likely to be affected in a different manner, and thus individualized medicine will be necessary.

As discussed at the summit, it has become clear that the physiological impact of diseases or their treatments can indeed accelerate the phenotypes of normal aging. Among those phenotypes, it is important to consider an increased susceptibility to additional major chronic diseases. Another area of research uncovered during the discussions pertains to the need to consider early exposure to disease as a possible confounder in studies focused on interventions that may reduce the rate of aging, again pointing to the need to consider individual differences in likely susceptibilities and needs.

Finally, the close relationship between the basic biology of aging and the basic biology of disease indicates the importance of fostering further interdisciplinary research, where scientists

This article is protected by copyright. All rights reserved. 
interested in different diseases might collaborate with researchers interested in aging to the enhanced benefit to both partners.
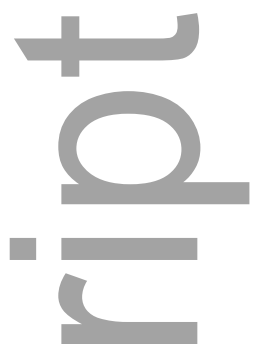

\section{Acknowledgments}

\section{Conflicts of Interest}

The authors declare no conflicts of interest

\section{References}

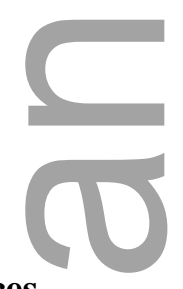

1. Burch JB, Augustine AD, Frieden LA, Hadley E, et al. Advances in geroscience: impact on healthspan and chronic disease. J Gerontol A Biol Sci Med Sci, 2014, Jun;69 Suppl 1:S1-3.

2. Kennedy BK, Berger SL, Brunet A, et al. Aging: a common driver of chronic diseases and a target for novel interventions Cell, 2014, 159(4): 709-713.

3. Diabetes Prevention Program Research Group. Reduction in the Incidence of Type 2 Diabetes with Lifestyle Intervention or Metformin. N Engl J Med, 2002, 346:393-403.

4. Bouchlaka MN, Sckisel GD, Chen M, Mirsoian A, et al. Aging predisposes to acute inflammatory induced pathology after tumor immunotherapy. J Exp Med, 2013, 210(11):2223-37.

5. Baker DJ, Wijshake T, Tchkonia T, LeBrasseur NK, et al. Clearance of p16Ink4a-positive senescent cells delays ageing-associated disorders. Nature, 2011, 479(7372): 232-6.

6. López-Otín C, Blasco MA, Partridge L et al.: The hallmarks of aging. 2013. Cell 153:11941217.

This article is protected by copyright. All rights reserved. 
7. Sierra F, Kohanski RA: Geroscience offers a new model for investigating the links between aging biology and susceptibility to aging-related chronic conditions. 2013. Public Policy \& Aging Report 23:7-9.

8. Austad SN: The geroscience hypothesis: Is it possible to change the rate of aging? in "Advances in Geroscience", Sierra and Kohanski eds., pp. 1-36, Springer, 2015

9. Kennedy BK, Berger SL, Brunet A, et al.: Geroscience: linking aging to chronic disease. 2014. Cell. 159:709-713.

10. Gardner EM. Caloric restriction decreases survival of aged mice in response to primary influenza infection. J Gerontol A Biol Sci Med Sci. 2005;60:688-694.

11. Sun D, Muthukumar AR, Lawrence RA, Fernandes G. Effects of calorie restriction on polymicrobial peritonitis induced by cecum ligation and puncture in young C57BL/6 mice. Clin Diagn Lab Immunol. 2001;8:1003-1011.

12. Lin JH. Applications and limitations of genetically modified mouse models in drug discovery and development. Curr Drug Metab. 2008;9:419-438.

13. Hall AM, Roberson ED. Mouse models of Alzheimer's disease. Brain Research Bulletin 2012;88:3-12.

14. Codd, V., Nelson, C. P., Albrecht, E., et al. 2013. Identification of seven loci affecting mean telomere length and their association with disease. Nature Genetics, 45(4), 422-427, 427e12. http://doi.org/10.1038/ng.2528

15. Tamura, Y., Takubo, K., Aida, J., Araki, A., \& Ito, H. (2016). Telomere attrition and diabetes mellitus. Geriatrics \& Gerontology International, 16 Suppl 1, 66-74. http://doi.org/10.1111/ggi.12738

16. Verhoeven, J. E., Révész, D., Epel, E. S. 2014. Major depressive disorder and accelerated cellular aging: results from a large psychiatric cohort study. Molecular Psychiatry, 19(8), 895-901.

17. Boccardi, V., Barbieri, M., Rizzo, M. R., Marfella, R., Esposito, A., Marano, L., \& Paolisso, G. (2013). A new pleiotropic effect of statins in elderly: modulation of telomerase activity. FASEB Journal: Official Publication of the Federation of American Societies for Experimental Biology, 27(9), 3879-3885. http://doi.org/10.1096/fj.13-232066

18. Lu, Y., Leong, W., Guérin, O., Gilson, E., \& Ye, J. (2013). Telomeric impact of conventional chemotherapy. Frontiers of Medicine, 7(4), 411-417. http://doi.org/10.1007/s11684-013$\underline{0293-z}$

19. Neigh, G.N., Rhodes, S.T., Valdez, A., Jovanovic, T., (2015) PTSD co-morbid with HIV: Separate but equal, or two parts of a whole? Neurobiology of Disease; [epud ahead of print].

This article is protected by copyright. All rights reserved. 
20. Ickovics, J.R., Hamburger, M.E., Vlahov, D., Schoenbaum, E.E., Schuman, P., Boland, R.J., Moore, J., HIV Epidemiology Research Study Group, (2001) Mortality, CD4 cell count decline, and depressive symptoms among HIV-seropositive women: longitudinal analysis from the HIV Epidemiology Research Study. JAMA; 285(11):1466-74.

21. Heywood, W., Lyons, A., (2016) HIV and Elevated Mental Health Problems: Diagnostic, Treatment, and Risk Patterns for Symptoms of Depression, Anxiety, and Stress in a National Community-Based Cohort of Gay Men Living with HIV. AIDS Behav; Feb 13 [epub ahead of print].

22. Panagiotakopoulos, L., Kelly, S., Neigh, G.N., (2015) IV-1 proteins accelerate HPA axis habituation in female rats. Physiology and Behavior; [epub ahead of print].

23. Kedem, E., Shahar, E., Hassoun, G., Pollack, S., (2010) Iatrogenic Cushing's syndrome due to coadministration of ritonavir and inhaled budesonide in an asthmatic human immunodeficiency virus infected patient. J. Asthma; 47(7):830-1.

24. Erlandson KM LX, Abraham AG, Margolick JB, Lake JE, Palella FJ, Koletar SL. Brown TT. . Long-term impact of HIV wasting on physical functio in the Multicenter AIDS Cohort Study. AIDS 2016,0:(in press).

25. Scherzer R, Heymsfield SB, Lee D, Powderly WG, Tien PC, Bacchetti P, et al. Decreased limb muscle and increased central adiposity are associated with 5-year all-cause mortality in HIV infection. AIDS 2011,25:1405-1414.

26. Gardner K, Hall PA, Chinnery PF, Payne BA. HIV treatment and associated mitochondrial pathology: review of 25 years of in vitro, animal, and human studies. Toxicol Pathol 2014,42:811-822.

27. Kusko RL, Banerjee C, Long KK, Darcy A, Otis J, Sebastiani P, et al. Premature expression of a muscle fibrosis axis in chronic HIV infection. Skelet Muscle 2012,2:10.

28. Natsag J, Sellmeyer D, Haberlen SA, Margolick JB, Jacobson LP, Palella F, et al. HIV infection is associated with increased thigh muscle cross-sectional area and lower muscle attenuation on CT in men age 40-70 years old. In: ENDO; Abstract FRI-229. San Diego, CA; 2015

29. McComsey GA, Moser C, Currier J, Ribaudo HJ, Paczuski P, Dube MP, et al. Body Composition Changes After Initiation of Raltegravir or Protease Inhibitors: ACTG A5260s. Clin Infect Dis 2016,62:853-862.

30. Erlandson KM, Lake JE. Fat Matters: Understanding the Role of Adipose Tissue in Health in HIV Infection. Curr HIV/AIDS Rep 2016,13:20-30.

31. Walker, R.G., et al., Biochemistry and Biology of GDF11 and Myostatin: Similarities, Differences, and Questions for Future Investigation. Circulation research, 2016. 118(7): p. 1125-42.

32. White, T.A. and N.K. LeBrasseur, Myostatin and sarcopenia: opportunities and challenges a mini-review. Gerontology, 2014. 60(4): p. 289-93.

This article is protected by copyright. All rights reserved. 
33. Harper, S.C., et al., Is Growth Differentiation Factor 11 a Realistic Therapeutic for AgingDependent Muscle Defects? Circulation research, 2016. 118(7): p. 1143-50.

34. McNally, E.M., Questions and Answers About Myostatin, GDF11, and the Aging Heart. Circulation research, 2016. 118(1): p. 6-8.

35. Lee, S.J., Extracellular Regulation of Myostatin: A Molecular Rheostat for Muscle Mass. Immunology, endocrine \& metabolic agents in medicinal chemistry, 2010. 10: p. 183-194.

36. Smith, R. L., et al. 2012. Premature and accelerated aging: HIV or HAART? Front Genet. 3: 328.

37. Caron, M., et al. 2008. Contribution of mitochondrial dysfunction and oxidative stress to cellular premature senescence induced by antiretroviral thymidine analogues. Antivir Ther.

$$
\text { 13: 27-38. }
$$

38. Blas-Garcia, A., et al. 2010. Inhibition of mitochondrial function by efavirenz increases lipid content in hepatic cells. Hepatology. 52: 115-125.

39. Wiley, C. D., et al. 2016. Mitochondrial Dysfunction Induces Senescence with a Distinct Secretory Phenotype. Cell Metab. 23: 303-314.

40. Baker, D. J., et al. 2016. Naturally occurring p16(Ink4a)-positive cells shorten healthy lifespan. Nature. 530: 184-189.

41. 1. Martinez-Maza O, Breen EC. B-cell activation and lymphoma in patients with HIV. Curr Opin Oncol 2002;14:528-32.

42. 2. Teschendorff AE, Menon U, Gentry-Maharaj A, Ramus SJ, Weisenberger DJ, Shen H, Campan M, Noushmehr H, Bell CG, Maxwell AP, Savage DA, Mueller-Holzner E, Marth C, Kocjan G, Gayther SA, Jones A, Beck S, Wagner W, Laird PW, Jacobs IJ, Widschwendter M. Age-dependent DNA methylation of genes that are suppressed in stem cells is a hallmark of cacner. Genome Research 2010;20:440-6.

43. 3. Rickabaugh TM, Baxter RM, Sehl M, Sinsheimer JS, Hultin PM, Hultin LE, Quach A, Martinez-MAza O, Horvath S, Vilain E, Jamieson BD. Acceleration of age-associated methylation patterns in HIV-1-infected adults. PLoS One 2015;10:e0119201.

This article is protected by copyright. All rights reserved. 
44. 4. Horvath S. DNA methylation age of human tissues and cell types. Genome Biology 2013; 14:R115.

45. Panes J, Kurose I, Rodriguez-Vaca D, Anderson DC, Miyasaka M, Tso P, Granger DN: Diabetes exacerbates inflammatory responses to ischemia-reperfusion. Circulation 1996;93:161-167

46. Salas A, Panes J, Elizalde JI, Casadevall M, Anderson DC, Granger DN, Pique JM: Mechanisms responsible for enhanced inflammatory response to ischemia- reperfusion in diabetes. The American journal of physiology 1998;275:H1773-1781

47. Wang Q, Xie Z, Zhang W, Zhou J, Wu Y, Zhang M, Zhu H, Zou MH: Myeloperoxidase deletion prevents high-fat diet-induced obesity and insulin resistance. Diabetes 2014;63:41724185

48. Ley K: Leukocyte Recruitment as Seen by Intravital Microscopy. In Physiology of Inflammation Ley K, Ed. New York, Oxford University Press, 2001, p. 303-337

49. Lefer DJ, Scalia R, Jones SP, Sharp BR, Hoffmeyer MR, Farvid AR, Gibson MF, Lefer AM: HMG-CoA reductase inhibition protects the diabetic myocardium from ischemia-reperfusion injury. Faseb J 2001;15:1454-1456

50. Russo HM, Wickenheiser KJ, Luo W, Ohman MK, Franchi L, Wright AP, Bodary PF, Nunez G, Eitzman DT: P-selectin glycoprotein ligand-1 regulates adhesive properties of the endothelium and leukocyte trafficking into adipose tissue. Circulation research 2010;107:388397

51. Marfella R, Esposito K, Giunta R, Coppola G, De Angelis L, Farzati B, Paolisso G, Giugliano D: Circulating adhesion molecules in humans: role of hyperglycemia and hyperinsulinemia. Circulation 2000;101:2247-2251

52. Glowinska B, Urban M, Peczynska J, Florys B: Soluble adhesion molecules (sICAM-1, sVCAM-1) and selectins ( $\mathrm{sE}$ selectin, sP selectin, sL selectin) levels in children and adolescents with obesity, hypertension, and diabetes. Metabolism 2005;54:1020-1026

53. Morigi M, Angioletti S, Imberti B, Donadelli R, Micheletti G, Figliuzzi M, Remuzzi A, Zoja $\mathrm{C}$, Remuzzi G: Leukocyte-endothelial interaction is augmented by high glucose

This article is protected by copyright. All rights reserved. 
concentrations and hyperglycemia in a NF-kB-dependent fashion. J Clin Invest 1998;101:1905-1915

54. Dosquet C, Weill D, Wautier JL: Molecular mechanism of blood monocyte adhesion to vascular endothelial cells. Nouv Rev Fr Hematol 1992;34 Suppl:S55-59

55. Kim JA, Berliner JA, Natarajan RD, Nadler JL: Evidence that glucose increases monocyte binding to human aortic endothelial cells. Diabetes 1994;43:1103-1107

56. Tsao PS, Niebauer J, Buitrago R, Lin PS, Wang BY, Cooke JP, Chen YD, Reaven GM: Interaction of diabetes and hypertension on determinants of endothelial adhesiveness. Arteriosclerosis, thrombosis, and vascular biology 1998;18:947-953

57. Valerio A, Cardile A, Cozzi V, Bracale R, Tedesco L, Pisconti A, Palomba L, Cantoni O, Clementi E, Moncada S, Carruba MO, Nisoli E: TNF-alpha downregulates eNOS expression and mitochondrial biogenesis in fat and muscle of obese rodents. The Journal of clinical investigation 2006;116:2791-2798

58. Kim F, Pham M, Maloney E, Rizzo NO, Morton GJ, Wisse BE, Kirk EA, Chait A, Schwartz MW: Vascular inflammation, insulin resistance, and reduced nitric oxide production precede the onset of peripheral insulin resistance. Arteriosclerosis, thrombosis, and vascular biology 2008;28:1982-1988

59. Kubes P, Suzuki M, Granger DN: Nitric oxide: an endogenous modulator of leukocyte adhesion. Proceedings of the National Academy of Sciences of the United States of America 1991;88:4651-4655

60. Lefer AM, Scalia R: Nitric oxide in inflammation. 2001, p. 447-472

61. Lakatta EG: Arterial and cardiac aging: major shareholders in cardiovascular disease enterprises: Part III: cellular and molecular clues to heart and arterial aging. Circulation 2003;107:490-497

62. Taddei S, Virdis A, Mattei P, Ghiadoni L, Gennari A, Fasolo CB, Sudano I, Salvetti A: Aging and endothelial function in normotensive subjects and patients with essential hypertension. Circulation 1995;91:1981-1987

This article is protected by copyright. All rights reserved. 
63. Egashira K, Inou T, Hirooka Y, Kai H, Sugimachi M, Suzuki S, Kuga T, Urabe Y, Takeshita A: Effects of age on endothelium-dependent vasodilation of resistance coronary artery by acetylcholine in humans. Circulation 1993;88:77-81

64. Kung CF, Luscher TF: Different mechanisms of endothelial dysfunction with aging and hypertension in rat aorta. Hypertension 1995;25:194-200

65. Hongo K, Nakagomi T, Kassell NF, Sasaki T, Lehman M, Vollmer DG, Tsukahara T, Ogawa $\mathrm{H}$, Torner J: Effects of aging and hypertension on endothelium-dependent vascular relaxation in rat carotid artery. Stroke; a journal of cerebral circulation 1988;19:892-897

66. Atkinson J, Tatchum-Talom R, Capdeville-Atkinson C: Reduction of endothelial function with age in the mesenteric arterial bed of the normotensive rat. British journal of pharmacology 1994;111:1184-1188

67. Cernadas MR, Sanchez de Miguel L, Garcia-Duran M, Gonzalez-Fernandez F, Millas I, Monton M, Rodrigo J, Rico L, Fernandez P, de Frutos T, Rodriguez-Feo JA, Guerra J, Caramelo C, Casado S, Lopez F: Expression of constitutive and inducible nitric oxide synthases in the vascular wall of young and aging rats. Circulation research 1998;83:279-286

68. Challah M, Nadaud S, Philippe M, Battle T, Soubrier F, Corman B, Michel JB: Circulating and cellular markers of endothelial dysfunction with aging in rats. The American journal of physiology 1997;273:H1941-1948

69. Chalupsky K, Cai H: Endothelial dihydrofolate reductase: critical for nitric oxide bioavailability and role in angiotensin II uncoupling of endothelial nitric oxide synthase. Proceedings of the National Academy of Sciences of the United States of America 2005;102:9056-9061

70. Hamilton CA, Brosnan MJ, McIntyre M, Graham D, Dominiczak AF: Superoxide excess in hypertension and aging: a common cause of endothelial dysfunction. Hypertension 2001;37:529-534

71. van der Loo B, Labugger R, Skepper JN, Bachschmid M, Kilo J, Powell JM, PalaciosCallender M, Erusalimsky JD, Quaschning T, Malinski T, Gygi D, Ullrich V, Luscher TF: Enhanced peroxynitrite formation is associated with vascular aging. The Journal of experimental medicine 2000;192:1731-1744

This article is protected by copyright. All rights reserved. 
72. Azhar S, Cao L, Reaven E: Alteration of the adrenal antioxidant defense system during aging in rats. The Journal of clinical investigation 1995;96:1414-1424

73. Dukan S, Farewell A, Ballesteros M, Taddei F, Radman M, Nystrom T: Protein oxidation in response to increased transcriptional or translational errors. Proceedings of the National Academy of Sciences of the United States of America 2000;97:5746-5749

74. Li Z, Froehlich J, Galis ZS, Lakatta EG: Increased expression of matrix metalloproteinase-2 in the thickened intima of aged rats. Hypertension 1999;33:116-123

75. Orlandi A, Marcellini M, Spagnoli LG: Aging influences development and progression of early aortic atherosclerotic lesions in cholesterol-fed rabbits. Arteriosclerosis, thrombosis, and vascular biology 2000;20:1123-1136

76. Morisaki N, Saito I, Tamura K, Tashiro J, Masuda M, Kanzaki T, Watanabe S, Masuda Y, Saito Y: New indices of ischemic heart disease and aging: studies on the serum levels of soluble intercellular adhesion molecule-1 (ICAM-1) and soluble vascular cell adhesion molecule-1 (VCAM-1) in patients with hypercholesterolemia and ischemic heart disease. Atherosclerosis 1997;131:43-48

77. Csiszar A, Ungvari Z, Edwards JG, Kaminski P, Wolin MS, Koller A, Kaley G: Aginginduced phenotypic changes and oxidative stress impair coronary arteriolar function. Circulation research 2002;90:1159-1166

78. 34. Csiszar A, Ungvari Z, Koller A, Edwards JG, Kaley G: Aging-induced proinflammatory shift in cytokine expression profile in coronary arteries. Faseb J 2003;17:1183-1185

79. Rom I, Scalia R: Aging-associated Calpain Activation Increases Leukocyte Trafficking in the Microcireulation. The FASEB Journal 2013;27:687.616

80. Coodley EL: Coronary artery disease in the elderly. Postgrad Med 1990;87:223-228

81. Kannel WB, Vokonas PS: Demographics of the prevalence, incidence, and management of coronary heart disease in the elderly and in women. Ann Epidemiol 1992;2:5-14

82. Dahlof B, Lindholm LH, Hansson L, Schersten B, Ekbom T, Wester PO: Morbidity and mortality in the Swedish Trial in Old Patients with Hypertension (STOP-Hypertension). Lancet 1991;338:1281-1285

This article is protected by copyright. All rights reserved. 
83. Gillum RF: Epidemiology of heart failure in the United States. American heart journal 1993;126:1042-1047

84. Rich MW: Epidemiology, pathophysiology, and etiology of congestive heart failure in older adults. J Am Geriatr Soc 1997;45:968-974

85. Satriano J, H. Mansoury, A. Deng, et al. 2010. Transition of kidney tubule cells to a senescent phenotype in early experimental diabetes. Am J Physiol Cell Physiol 299: C374-C380.

86. Wu J, R. Zhang, M. Torreggiani, et al. 2010. Induction of diabetes in aged C57B6 mice results in severe nephropathy. Am J Pathol 176: 2163-2176.

87. Miyazawa M, T. Ishii, K. Yasuda, et al. 2009. The role of mitochondrial superoxide anion on physiological aging in C57BL/6J mice. J Radiat Res 50: 73-82.

88. Dugan LL, Y_H You, S. S. Ali, et al. AMPK dysregulation promotes diabetes-related reduetion of superoxide and mitochondrial function. 2013. J Clin Invest 123: 4888-4899.

89. Wiggins JE, SR Patel, KA Shedden, et al. NFkB promotes inflammation, coagulation and fibrosis in the aging glomerulus. 2010. J Am Soc Nephrol 21: 587-597.

90. Sataranatarajan K, Y. Ikeno, A. Bokov, et al. Rapamycin increases mortality in db.db mice, a mouse model of type 2 diabetes. 2015. J Gerontol A Biol Sci Med Sci. 2015 Oct 5. pii: glv170. [Epub ahead of print]

91. Li F, Y. Zhou, H. Cao, et al. Autophagy attenuates diabetic glomerular damage through protection of hyperglycemia-induced podocyte damage. 2013. PLoS ONE 8: e60546

92. Kume S, T. Uzu, K. Horiike, et al. 2010. Calorie restriction enhances cell adaptation to hypoxia through Sirt1-dependent mitochondrial autophagy in mouse aged kidney. J Clin Invest 120: 1043-1055.

93. Yuan P, H. Xue, L. Zhou, et al. 2011. Rescue of mesangial cells from high glucose-induced over-proliferation and extracellular matrix secretion by hydrogen sulfide. Nephrol Dial Transplant 26: 2119-2126.

This article is protected by copyright. All rights reserved. 
94. Lee HJ, MM Mariappan, D. Feliers, et al. 2012. Hydrogen sulfide inhibits high glucoseinduced matrix protein synthesis by activating AMP-activated protein kinase in renal epithelial cells. J Biol Chem 287: 4451-2261.

95. Hine C, E. Harputlugil, Y. Zhang, et al. 2015. Endogenous hydrogen sulfide production is essential for dietary restriction benefits. Cell 160: 132-144.

96. Patschan D, K. Schwarze, E. Henze, et al. 2014. eEOC-mediated modulation of endothelial autophagy, senescence, and EnMT in murine diabetic nephropathy. Am J Physiol Renal Physiol 307: F686-694.

97. Yang H-C, M. Rossini, L-J Ma, et al. 2011. Cells derived from young bone marrow alleviate renal aging. J Am Soc Nephrol 22: 2028-2036.

98. Miao F, Z. Chen, S. Genuth, et al. 2014. Evaluating the role of epigenetic histone modifications in the metabolic memory of type 1 diabetes. Diabetes 1748-1762.

99. Halter, J.B.: Aging and Insulin Secretion. In: Handbook of the Biology of Aging, 7th Edition. Eds. E.J. Masoro and S.N. Austad, Elsevier Inc., 2011; pp. 373-384.

100. Maedler, K., Schumann, D.M., Schulthess, F., Oberholzer, J., Bosco, D., Berney, T., Donath, M.Y.(2006). Aging correlates with decreased $\beta$-cell proliferative capacity and enhanced sensitivity to apoptosis: a potential role for Fas and pancreatic duodenal homeobox-1. Diabetes, 55, 2455-2462.

101. Rankin, M., Kushner, J. (2009). Adaptive $\beta$-cell proliferation is severely restricted with advanced age. Diabetes, 58, 1365-1372.

102. Tschen, S-I., Sangeeta Dhawan, Tatyana Gurlo, and Anil Bhushan, (2009). Age-dependent decline in beta-cell proliferation restricts the capacity of $\square$-cell regeneration in mice. Diabetes, 58, 1312-1320.

103. Krishnamurthy $\mathbf{J}$ et al: p16ink4a induces an age-dependent decline in islet regenerative potential. Nature 443:453-457, 2006.

104. Chang \& Halter. 2003. AJP 284:E7-E12

This article is protected by copyright. All rights reserved. 
105. Cohen HJ, Harris T, Pieper CF. Coagulation and activation of inflammatory pathways in the development of functional decline and mortality in the elderly. Am J Med 2003;

114(3): 180-187.

106. Hanahan D, Weinberg RA. Hallmarks of Cancer: The Next Generation. Cell 2011; 144: 646-674.

107. López-Otín C, Blasco MA, Partridge L, Serrano M, Kroemer G. The Hallmarks of Aging. Cell 2013; 153: 1194-1217.

108. Robson SC, Shephard EG, Kirsch RE. Fibrin degradation product D-dimer induces the synthesis and release of biologically active IL-1 beta, IL-6 and plasminogen activator inhibitors from monocytes in vitro. Br J Haematol 1994; 86(2):322-326.

109. Schouten M, Wiersinga WJ, Levi M, van der Poll T. Inflammation, endothelium, and coagulation in sepsis. J Leukoc Biol 2008; 83: 536-545.

110. Mitnitski A, Collerton J, Martin-Ruiz C, Jagger C, von Zglinicki T, Rockwood K, Kirkwood TB. Age-related frailty and its association with biological markers of ageing. BMC Med. 2015; 13:161.

111. Redon CE, Dickey JS, Nakamura AJ, Kareva IG, Naf D, Nowsheen S, Kryston TB, Bonner WM, Georgakilas AG, Sedelnikova OA (2010) Tumors induce complex DNA damage in distant proliferative tissues in vivo. Proc Natl Acad Sci USA 107:17992-17997

112. Bilynsky BT, Dzhus MB, Litvinyak RI (2015) The conceptual and clinical problems of paraneoplastic syndrome in oncology and internal medicine. Exp Oncol 37:82-88

113. Hudson MM, Ness KK, Gurney JG, Mulrooney DA, Chemaitilly W, Krull KR, Green DM, Armstrong GT, Nottage KA, Jones KE, Sklar CA, Srivastava DK, Robison LL (2013) Clinical ascertainment of health outcomes among adults treated for childhood cancer. JAMA 309:2371-2381

114. Coppe JP, Patil CK, Rodier F, Sun Y, Munoz D, Goldstein J, Nelson PS, Desprez PY, Campisi J (2008) Senescence-associated secretory phenotypes reveal cell non-automous functions of oncogenic RAS and the p53 tumor suppressor. PLoS Biol 6:2853-2868

115. Campisi J (2013) Aging, cellular senescence, and cancer. Annu Rev Physiol 75:685705

116. Freund A, Orjalo A, Desprez PY, Campisi J (2010) Inflammatory networks during cellular senescence: causes and consequences. Trends Molec Med 16:238-248

This article is protected by copyright. All rights reserved. 
117. Chang J, Wang Y, Shao L, Laberge RM, Demaria M, Campisi J, Janakiraman K, Sharpless NE, Ding S, Feng W, Luo Y, Wang X, Aykin-Burns N, Krager K, Ponnappan U, Hauer-Jensen M, Meng A, Zhou D (2016) Clearance of senescent cells by ABT263 rejuvenates aged hematopoietic stem cells in mice. Nature Med 22:78-83

118. DeSantis, C.E., C.C. Lin, A.B. Mariotto, et al. 2014. Cancer treatment and survivorship statistics, 2014. CA Cancer J Clin 64:252-71.

119. Demark-Wahnefried, W., B.L. Peterson, E.P. Winer, et al. 2001. Changes in weight, body composition, and factors influencing energy balance among premenopausal breast cancer patients receiving adjuvant chemotherapy. J Clin Oncol 19:2381-9.

120. Newton, R.U. \& D.A. Galvao. 2008. Exercise in prevention and management of cancer. Curr Treat Options Oncol 9:135-46.

121. Hewitt, M., J.H. Rowland \& R. Yancik. 2003. Cancer survivors in the United States: age, health, and disability. J Gerontol A Biol Sci Med Sci 58:82-91.

122. Morey, M.C., D.C. Snyder, R. Sloane, et al. 2009. Effects of home-based diet and exercise on functional outcomes among older, overweight long-term cancer survivors: RENEW: a randomized controlled trial. JAMA 301:1883-91.

123. Ahles, T.A., J.C. Root, E.L. Ryan. 2012. Cancer- and cancer treatment-associated cognitive change: An update on the state of the science. Journal of Clinical Oncology 30: 3675-3686.

124. Sanoff, H.K., A.M. Deal, J. Krishnamurthy, et al. 2014. Effect of cytotoxic chemotherapy on markers of molecular age in patients with breast cancer. Journal of the National Cancer Institute 106:dju05

125. Salas-Ramirez K.Y., C. Bagnall, L. Frias, et al. 2015. Doxorubicin and cyclophosphamide induce cognitive dysfunction and active the ERK and AKT signaling pathways. Behavioural Brain Research 292: 133-141.

126. Ash J.A., P.R. Rapp. 2014. A quantitative neural network approach to understanding aging phenotypes. Ageing Research Reviews 15: 44-50.

127. McEwen B.S. 2016. In pursuit of resilience: Stress, epigenetics, and brain plasticity. Annals of the New York Academy of Sciences. doi: 10.1111/nyas.13020

This article is protected by copyright. All rights reserved. 
128. Tancredi M, Rosengren A, Svensson AM, Kosiborod M, Pivodic A, Gudbjörnsdottir S, Wedel H, Clements M, Dahlqvist S, Lind M. Excess Mortality among Persons with Type 2 Diabetes. N Engl J Med. 2015 Oct 29;373(18):1720-32.

129. Barzilai N, Ferrucci L. Insulin resistance and aging: a cause or a protective response? J Gerontol A Biol Sci Med Sci. 2012 Dec;67(12):1329-31.

130. Martin-Montalvo A, Mercken EM, Mitchell SJ, Palacios HH, Mote PL, ScheibyeKnudsen M, Gomes AP, Ward TM, Minor RK, Blouin MJ, Schwab M, Pollak M, Zhang Y, Yu Y, Becker KG, Bohr VA, Ingram DK, Sinclair DA, Wolf NS, Spindler SR, Bernier M, de Cabo R. Metformin improves healthspan and lifespan in mice. Nat Commun. 2013;4:2192.

131. Harrison DE, Strong R, Allison DB, Ames BN, Astle CM, Atamna H, Fernandez E, Flurkey K, Javors MA, Nadon NL, Nelson JF, Pletcher S, Simpkins JW, Smith D, Wilkinson JE, Miller RA. Acarbose, $17-\alpha$-estradiol, and nordihydroguaiaretic acid extend mouse lifespan preferentially in males. Aging Cell 2014 Apr;13(2):273-82.

132. Effect of intensive blood-glucose control with metformin on complications in overweight patients with type 2 diabetes (UKPDS 34). UK Prospective Diabetes Study (UKPDS) Group. Lancet 1998;352(9131):854-65.

133. Gandini S, Puntoni M, Heckman-Stoddard BM, Dunn BK, Ford L, DeCensi A, Szabo E. Metformin and cancer risk and mortality: a systematic review and meta-analysis taking into account biases and confounders. Cancer Prev Res (Phila). 2014;7(9):867-85.

134. Bannister CA, Holden SE, Jenkins-Jones S, Morgan CL, Halcox JP, Schernthaner G, Mukherjee J, Currie CJ. Can people with type 2 diabetes live longer than those without? A comparison of mortality in people initiated with metformin or sulphonylurea monotherapy and matched, non-diabetic controls. Diabetes Obes Metab. 2014;16(11):1165-73.

135. Chiasson JL, Josse RG, Gomis R, Hanefeld M, Karasik A, Laakso M; Acarbose for prevention of type 2 diabetes mellitus: the STOP-NIDDM randomised trial. STOP-NIDDM Trail Research Group. Lancet 2002 Jun 15;359(9323):2072-7.

136. Huffman DM, Farias Quipildor G, Mao K, Zhang X, Wan J, Apontes P, Cohen P, Barzilai N. Central insulin-like growth factor-1 (IGF-1) restores whole-body insulin action in a model of age-related insulin resistance and IGF-1 decline. Aging Cell 2015 Nov 4.

137. Lopez-Otin C, Blasco MA, Partridge L et al. The hallmarks of aging. Cell 2013; 153: 1194-1217.

138. Keating NL, Norredam M, Landrum MB et al. Physical and mental health status of older long-term cancer survivors. J Am Geriatr Soc 2005; 53: 2145-2152.

139. Hewitt M, Rowland JH, Yancik R. Cancer survivors in the United States: age, health, and disability. J Gerontol A Biol Sci Med Sci 2003; 58: 82-91.

This article is protected by copyright. All rights reserved. 
140. Moncayo R, Rudisch A, Diemling M, Kremser C. In-vivo visualisation of the anatomical structures related to the acupuncture points Dai mai and Shen mai by MRI: a single-case pilot study. BMC Med Imaging 2007; 7: 4.

141. Reeve BB, Potosky AL, Smith AW et al. Impact of cancer on health-related quality of life of older Americans. J Natl Cancer Inst 2009; 101: 860-868.

142. Weaver KE, Forsythe LP, Reeve BB et al. Mental and physical health-related quality of life among U.S. cancer survivors: population estimates from the 2010 National Health Interview Survey. Cancer Epidemiol Biomarkers Prev 2012; 21: 2108-2117.

143. Baker F, Haffer SC, Denniston M. Health-related quality of life of cancer and noncancer patients in Medicare managed care. Cancer 2003; 97: 674-681.

144. Mariotto AB, Rowland JH, Ries LA et al. Multiple cancer prevalence: a growing challenge in long-term survivorship. Cancer Epidemiol Biomarkers Prev 2007; 16: 566-571.

145. Mandelblatt JS, Jacobsen PB, Ahles T. Cognitive effects of cancer systemic therapy: implications for the care of older patients and survivors. J Clin Oncol 2014; 32: 2617-2626.

146. Wildiers H, Heeren P, Puts M et al. International Society of Geriatric Oncology consensus on geriatric assessment in older patients with cancer. J Clin Oncol 2014; 32: 25952603

147. Beeharry N, Broccoli D. Telomere dynamics in response to chemotherapy. Curr Mol Med 2005; 5: 187-196.

148. Diker-Cohen T, Uziel O, Szyper-Kravitz M et al. The effect of chemotherapy on telomere dynamics: clinical results and possible mechanisms. Leuk Lymphoma 2013; 54: 2023-2029.

149. Yoon SY, Sung HJ, Park KH et al. Telomere length shortening of peripheral blood mononuclear cells in solid-cancer patients undergoing standard-dose chemotherapy might be correlated with good treatment response and neutropenia severity. Acta Haematol 2007; 118: $30-37$.

150. Unryn BM, Hao D, Gluck S, Riabowol KT. Acceleration of telomere loss by chemotherapy is greater in older patients with locally advanced head and neck cancer. Clin Cancer Res 2006; 12: 6345-6350.

151. Sanoff HK, Deal AM, Krishnamurthy J et al. Effect of Cytotoxic Chemotherapy on Markers of Molecular Age in Patients With Breast Cancer. J Natl Cancer Inst 2014.

152. Pomykala KL, Ganz PA, Bower JE et al. The association between pro-inflammatory cytokines, regional cerebral metabolism, and cognitive complaints following adjuvant chemotherapy for breast cancer. Brain Imaging Behav 2013; 7: 511-523.

This article is protected by copyright. All rights reserved. 
153. Kim DW, Chung K, Chung WK et al. Risk of secondary cancers from scattered radiation during intensity-modulated radiotherapies for hepatocellular carcinoma. Radiat Oncol 2014; 9: 109.

154. Caro MM, Laviano A, Pichard C, Candela CG. [Relationship between nutritional intervention and quality of life in cancer patients]. Nutr Hosp 2007; 22: 337-350.

155. Aoyagi T, Terracina KP, Raza A et al. Cancer cachexia, mechanism and treatment. World J Gastrointest Oncol 2015; 7: 17-29.

156. Brenchley JM, Price DA, Schacker TW, et al. Microbial translocation is a cause of systemic immune activation in chronic HIV infection. Nat Med 2006; 12:1365-1371.

157. Hunt PW, Sinclair E, Rodriguez B, et al. Gut Epithelial Barrier Dysfunction and Innate Immune Activation Predict Mortality in Treated HIV Infection. J Infect Dis 2014.

158. Rera M, Clark RI, Walker DW. Intestinal barrier dysfunction links metabolic and inflammatory markers of aging to death in Drosophila. Proc Natl Acad Sci U S A 2012; 109:21528-33.

159. Tran L, Greenwood-Van Meerveld B. Age-associated remodeling of the intestinal epithelial barrier. J Gerontol A Biol Sci Med Sci 2013; 68:1045-56.

160. Katz D, Hollander D, Said HM, Dadufalza V. Aging-associated increase in intestinal permeability to polyethylene glycol 900. Dig Dis Sci 1987; 32:285-8.

161. van der Goot AT, Nollen EA. Tryptophan metabolism: entering the field of aging and age-related pathologies. Trends Mol Med 2013; 19:336-44.

162. Vujkovic-Cvijin I, Dunham RM, Iwai S, et al. Dysbiosis of the Gut Microbiota Is Associated with HIV Disease Progression and Tryptophan Catabolism. Science Translational Medicine 2013; 5:193ra91.

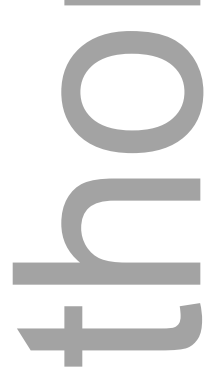

Figure legends

This article is protected by copyright. All rights reserved. 
Figure 1. The pillars of geroscience. Adapted from Refs. 1 and 2.

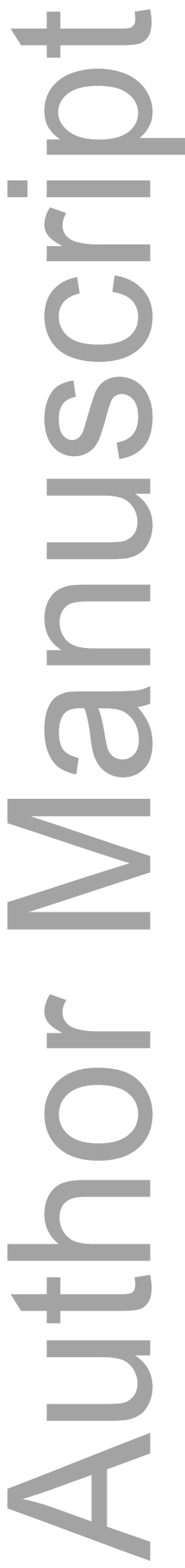

This article is protected by copyright. All rights reserved. 


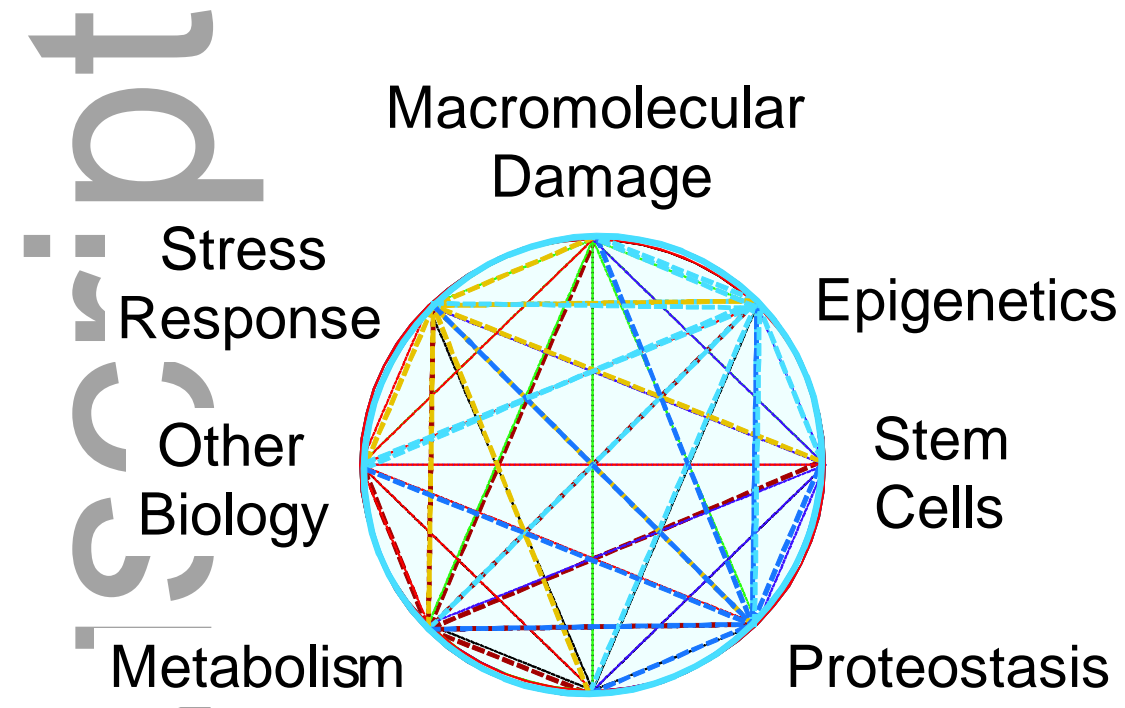

Inflammation/Senescence

This article is protected by copyright. All rights reserved. 
Figure 2. Model for age-related hyperglycemia. Reprinted from Ref. 104.

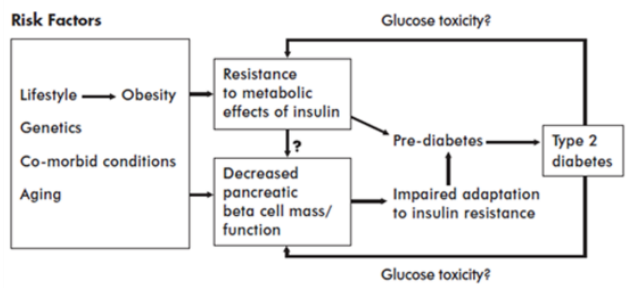

Figure 3. Inflammation/coagulation in cancer and aging.

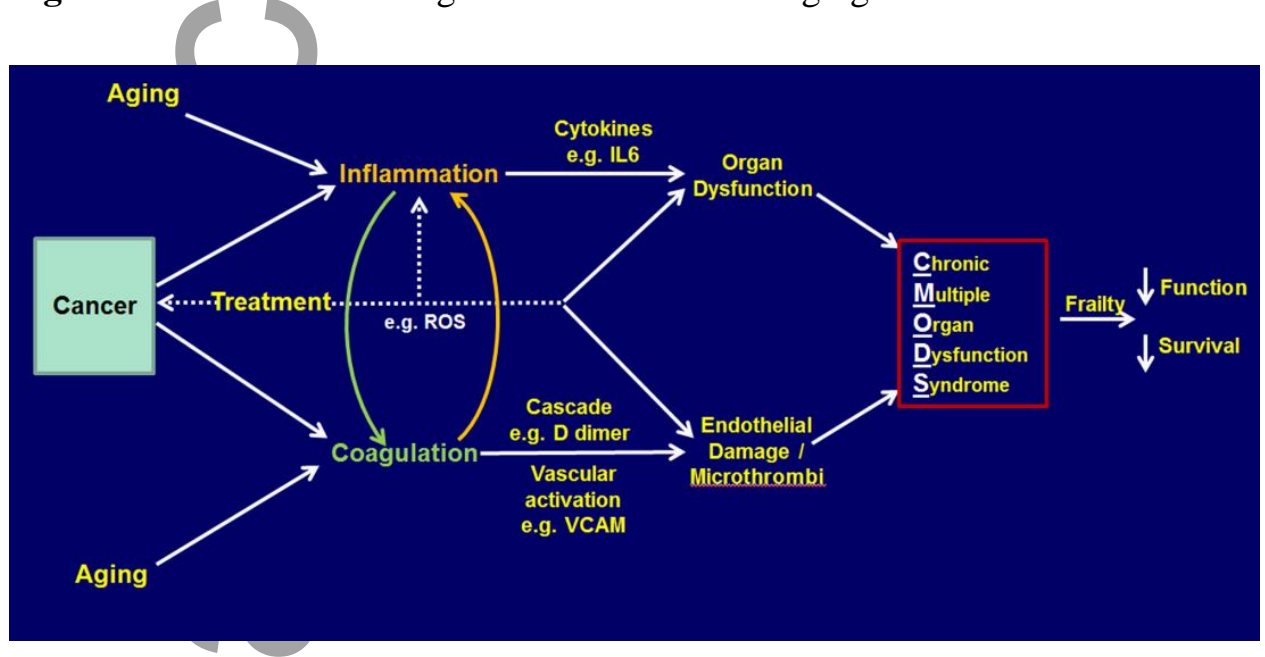

Figure 4. Kilogram change in fat (dashed line) and lean (solid line) body mass among 36 breast cancer patients receiving adjuvant chemotherapy. Adapted from Ref. 119.

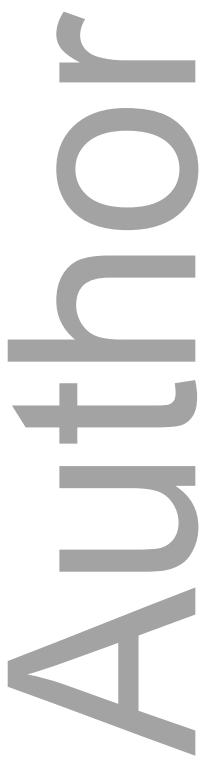

This article is protected by copyright. All rights reserved. 

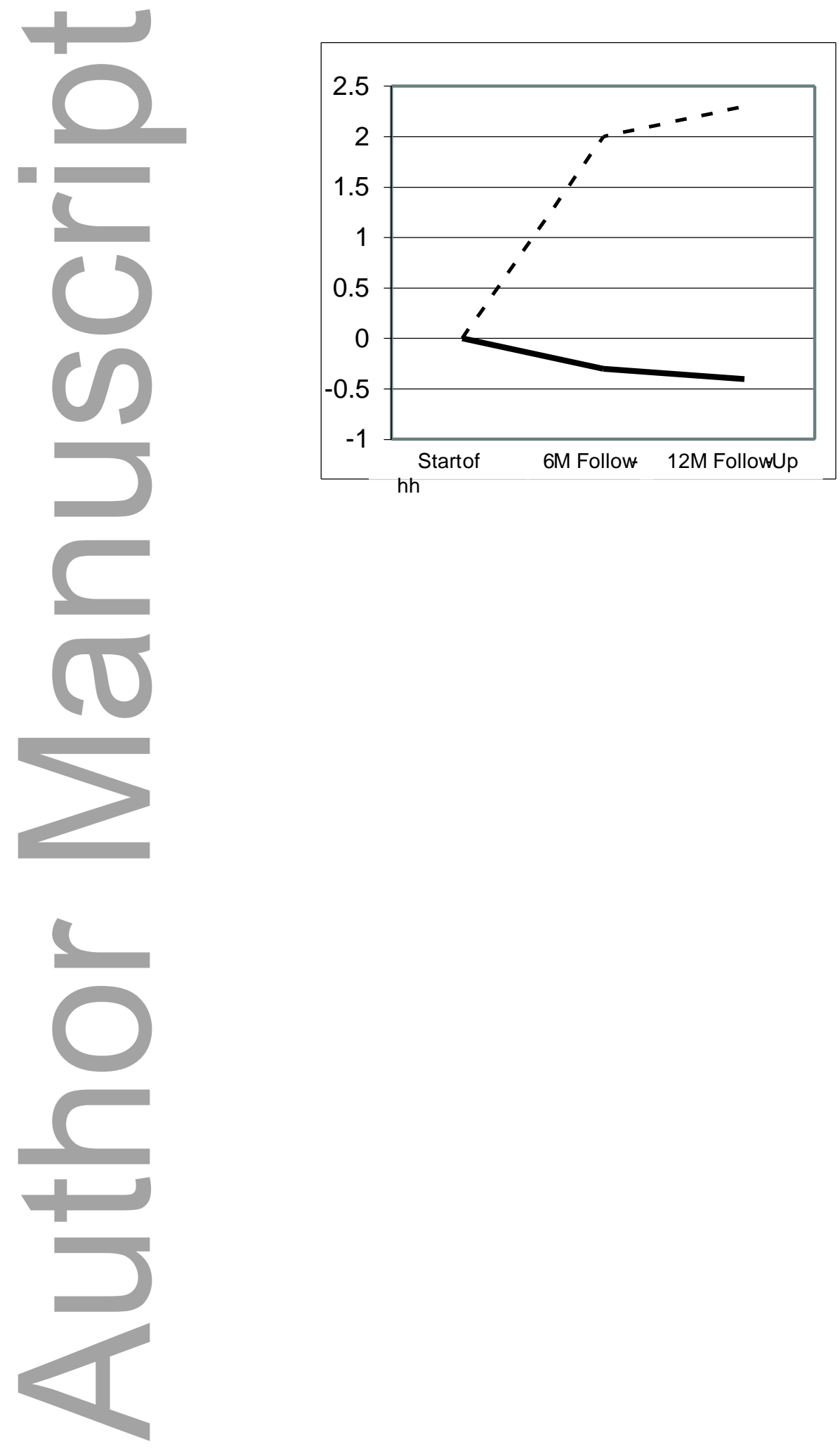

This article is protected by copyright. All rights reserved. 